\title{
A Clinical Characters and Prognosis Analysis on 15 Cases With Malignant Melanoma in the Head and Neck
}

\section{Xiaodong Liu (D 615840785@qq.com )}

Sheng Jing Hospital

Weixian Liu

Sheng Jing Hospital

Qiuxu Wang

Sheng Jing Hospital

\section{Research Article}

Keywords: Malignant Melanoma, Clinical manifestation, Treatment, Prognosis

Posted Date: December 10th, 2020

DOl: https://doi.org/10.21203/rs.3.rs-120767/v1

License: () (1) This work is licensed under a Creative Commons Attribution 4.0 International License. Read Full License 


\section{Abstract}

Objective: We analyze the pathogenesis, clinical characteristics, diagnosis, treatment and histological feature of Malignant Melanoma in the head and neck. To improve the understanding and help the early diagnosis and treatment of the disease. As a result, improve the treatment and prognosis of Malignant Melanoma in head and neck.

Method: We collect 15 cases of Malignant Melanoma in the head and neck region treated in the Department of Oral and Maxillofacial Surgery in Shengjing Hospital of China Medical University. All data were obtained from patient's medical records which including the pathogenesis, clinical and histological features, diagnosis, treatment and prognosis.

Result: This study included 15 cases, there are 9 male and 6 female patients. The average age is 62.9 years lid, the oldest one is 75 years old and the youngest one is 40 years old. 2 cases occurred in the lip, 2 cases occurred in the tongue, 2 cases occurred in the submandibular area, 1 cases occurred in the parotid gland, 1 case occurred in the neck, other 7 cases occurred in the gingiva. The cases occurred in the lip, gingiva, tongue, parotid gland and submandibular area are primary tumor, cases occurred in neck were metastasis. 6 cases were treated by surgical excision. 1 cases occurred in gingiva was treated by surgical excision combine with chemotherapy. 5 years followed up has been taken. 10 cases were dead because of recurrence and metastasis in 5 years after the operation. 5 patients do not have a relapse and still alive.

Conclusion: Malignant Melanoma in the head and neck are mostly affected the old people. In this study gingiva is the most commonly primary site, neck is the most commonly transferring site. The diagnosis of malignant Melanoma is mainly relying on the clinical manifestation and pathological examination. Histopathological examination is considered the golden standard for diagnosis. Surgical excision combined with chemotherapy is the main treatment modality for Malignant Melanoma. Cryotherapy and immunotherapy also have been used in the treatment. The prognosis of Malignant Melanoma is poor. So early detection and early treatment is important in the treatment.

\section{Introduction}

Malignant Melanoma is a rare malignant neoplasms arising from melanocytes, It usually occurred at skin and mucosa of oral, respiratory tract and digestive tract which accounts for $1 \%-2 \%$ of all malignant tumors. Malignant melanoma usually occurs in white people, the prevalence rate of Malignant Melanoma in Asian people is low. In recent years, the incidence rate of Malignant Melanoma is increasing worldwide. Malignant Melanoma is a high-grade malignant tumor, distant metastasis may occur in the early stage of Malignant Melanoma and usually has poor prognosis ${ }^{[1]}$. Malignant Melanoma of head and neck can affect skin and mucosa of head and neck, Malignant Melanoma which occur in oral mucosa are more common than those occur in skin and it usually affect gingiva and palatal mucosa. Compared with those occurred in skin, Malignant Melanoma which occurred in oral mucosa has higher grade malignancy, 
stronger invasion, poorer prognosis. About $30 \%$ of all patients has lymph node metastasis or distant metastasis $^{[2]}$. The causes of Malignant Melanoma are various, which include hereditary, ethnic, ultraviolet irradiation, traumatic and virus infection. Malignant Melanoma mostly occur in old people, male patients are more common than female patients. Most of the clinical manifestations of Cutaneous malignant melanoma are the sudden enlargement of the lesion, darker of the color and superficial ulcer of the lesion. In the early stage of mucosal Malignant Melanoma, the clinical symptoms usually are dark lesions, ulcer and bleeding ${ }^{[3]}$. The main methods for diagnosis of Malignant Melanoma are clinical manifestation and pathological examination, pathological examination is still the main method for a definite diagnosis. Recent years, as the rapid development of molecular biology techniques, molecular diagnosis began to use in the diagnosis of Malignant Melanoma ${ }^{[4]}$. Now surgical treatment is the main method for the treatment of Malignant Melanoma, which include the resection of the primary site and dissection of lymph nodes. The treatment also include cryosurgery, radiotherapy, chemotherapy, biotherapy and immunotherapy. In recent years, more and more researchers pay attention to the target therapy of Malignant Melanoma ${ }^{[5]}$. Malignant Melanoma of head and neck has poor prognosis, most patients had lymph node or distant metastasis at first visit. So early diagnosis and early treatment are very important in the diagnosis and treatment. In this study, we collect 15 Malignant Melanoma of head and neck patients treated at Shengjing Hospital from January 2008 to December 2018, retrospectively analyze their medical records, study the relationship between clinical features and prognosis, improve the standardized diagnosis and treatment level of Malignant Melanoma of head and neck.

\section{Materials And Methods}

Analyze the medical records of Malignant Melanoma of head and neck patients diagnosed in Shengjing Hospital of China Medical University. All patients finish the clinical, radiological and laboratory examination, the typical clinical symptoms and signs are the main methods for the diagnosis of Malignant Melanoma. Pathological examination is the gold standard for a definite diagnosis, immunohistochemical examination is the main assistant method for diagnosis ${ }^{[6]}$.

\subsection{Inclusion Criteria}

Patients which made a definite diagnosis by histological examination ${ }^{[5]}$; patients with a complete medical records; make sure that head and neck as the primary site through physical examination and assistant examination; laboratory examinations include the blood and urine routine examinations and the hepatic and renal functions test, radiological examinations include ultrasound, CT, MRI of regional lymph node, CT or Xray of chest and CT or MRI of primary site; clearly recorded of name, gender, age, clinical and histological diagnosis, location of the lesion and treatment method of the patients.

\subsection{Exclusion criteria}

Has other systematic diseases such as serious cardiocerebral vascular diseases or serious diabetes; has other malignant tumors; has psychonosema; incomplete medical records or unclear histological 
diagnosis; die of other diseases.

\subsection{Data collection and follow-up}

Collect medical records of patients which was diagnosed as Malignant Melanoma of head and neck from Hospital Information System of Shengjing hospital of China Medical University from January 2008 to December 2018. Record the age, gender, primary site, possibility of lymph node metastasis, treatment methods and prognosis of patients. Primary sites include parotid, neck, submandibular area, tongue and gingiva. Predict the possibility of lymph node metastasis based on the preoperative clinical and radiological examination. Methods of treatment include surgical treatment, cryosurgery and chemotherapy. Method of follow-up for patients include in-hospital examine, telephone and return to hospital for review. Follow-up contents include number of treatments, recurrence, lymph node metastasis, distant metastasis and survival time. Calculate 5-year survival rate of patients and analyze the condition of recurrence and metastasis of patients. The follow-up period ended February 2020. In this study the prognosis of patients is determined by overall survival of patients, it influenced by several factors which include gender, age, site of lesion ${ }^{[6]}$. Survival analysis of patients is evaluated by overall survival(OS), OS is defined as from the day that make a definite diagnosis to the day that death of the patient or follow-up ended, related prognostic factors also be analyzed.

\subsection{Statistic method}

Analyzed by SPSS18.0 software, survival analysis is analyzed by Kaplan-Meier method, among that the single-factor survival rate is compared by log-rank method, $\mathrm{P} \otimes 0.05$ is statistically significant, multi-factor comparation is analyzed by Cox proportional hazards model. Because in this study the sample size is small, so the result is suggestive, in the conditional case, the sample size should be augmented for further study.

\section{Result}

\subsection{Basic situation of the research objects}

There are 15 patients diagnosed as Malignant Melanoma of head and neck in Shengjing hospital of China Medical University from January 2008 to December 2018. There are 9 male patients account for $60 \%$ and 6 female patients accounts for $40 \%$. The youngest is 40 years old and the oldest is 75 years old. The average age is 62.9 years old. Lip, tongue and submandibular each has two cases, there are two cases occur in parotid and neck respectively, the other 7 cases occur in gingiva. Malignant Melanoma which occur in lip, submandibular region, parotid, tongue and gingiva are primary tumors, lesions occur in neck are metastasis tumors. 6 cases treated only by surgical method, 1 case occurred in gingiva treated by cryosurgery combined with surgical treatment and chemotherapy, 8 cases treated by surgical treatment and chemotherapy. Among 10 patients 2 cases had smoking history, 2 cases had a history of hypertension, 1 case had a history of laser surgery, a case had inappropriate prothesis and 2 cases had lung metastases when diagnosed(Table 1). 


\subsubsection{Preoperative Examination}

Cases occur in gingiva and lip had CT of maxilla and mandible, cases occur in parotid had CT examination of parotid gland, cases occur In neck or cases which had possible cervical lymph node metastasis had CT or MRI of neck, cases which had possible lung metastasis had lung CT screening and all patients had preoperative conventional examination(Figure 1).

\subsubsection{Treatment Method}

In 15 cases, 6 cases treated only by surgical method, 1 cases origin from gingiva treated by cryosurgery combined with surgery and chemotherapy, 8 cases treated by surgery combined with chemotherapy, surgical treatment include local resection and nek lymph node dissection. Patients which received chemotherapy in our hospital were treated by DTIC, 1 time a month, four times in all.

\subsubsection{Pathological examination}

All 15 patients received histological and immunohistochemistry examination. Histological examination shows that the tumor cells showed spindle shaped, sheet arranged and mitotic figures visible. Immunohistochemistry examination showed that: S-100 can be seen in all 15 patients which accounting for $100 \%$, HMB45 can be seen in 12 patients which accounting for $80 \%$, Melan-A can be seen in 10 patients which accounting for $66.66 \%$, Vimentin can be seen in 7 patients which accounting for $46.66 \%$ (Figure 2,3).

\subsubsection{Follow-up}

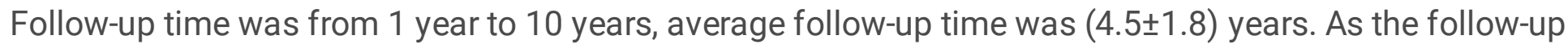
period ended, 5 patients survived, 10 patients died from the disease. In those patients, the 1-year,2-year and 5 -yearsurvival rate are $82.3 \%, 54.7 \%$ and 16.8 respectively, the median survival for those patients was 30.5 months.

\subsection{Survival analysis}

\subsubsection{Relationship between prognosis and gender}

Of the 10 cases, 9 patients were male and 6 patients were female. The average age of male patients were 30.8 months, the average age of female patients are 30.2 months, after the univariate analysis, the effect of sex on prognosis had no significant difference $(P=0.709 \llbracket 0.05)$ (Figure 4).

\subsubsection{The relationship between prognosis and age}

In this study the age of those patients were from 40 to 75 years old, the average age was 62 years old. Divided the patients into two groups, there were 10 patients aged less than or equal to 60 years old and 7 patients survived by the end of the follow-up period, the median survival time was 31.5 months. There were 5 patients aged more than 60 years old and 3 patients survived, the median survival time was 29.5 
months, it suggested that the effect of age on prognosis had no significant difference $(P=0.630 \rrbracket 0.05)$. (Figure 5).

\subsubsection{The relationship between prognosis and primary sites}

In all 15 patients there were 7 cases origin from oral mucosa and the median survival time was 28.7 months. There were 8 cases origin from non- oral mucosa and the median survival time was 32.2 months. It had significant difference between patients which had different primary sites $(P=0.022 \otimes 0.05)$, it suggested that patients which origin from oral mucosa had poor prognosis than patients which origin from non-oral mucosa(Figure 6).

\subsubsection{The relationship between prognosis and treatment method}

In 15 patients there were 6 patient treated only by surgery, 1 patient origin from gingiva treated by cryosurgery combined with surgical treatment and chemotherapy, 8 patients treated by surgical treatment and chemotherapy. The median survival time of patients which received chemotherapy was 33.5 months, the median survival time of patients which did not received chemotherapy were 29.0 months, the difference between these two group was not statistically significant $(P=0.987 \otimes 0.05)$ (Figure 7).

\subsubsection{The relationship between prognosis and lymph node metastasis}

In 15 patients there were 8 patients were found cervical lymph node metastasis at their first visit, the median survival time is 28.9 months. There were 7 patients which not found cervical lymph node metastasis at their first visit and the median survival time was 30.8 months, the difference between these two group was not statistically significant $(P=0.987 \rrbracket 0.05)$. (Figure 8 ).

\subsubsection{The relationship between prognosis and the expression of immune markers}

All 15 patients were performed by immunohistochemical examination, HMB45 was expressed in 12 patients and the difference was not statistically significant $(P=0.820 \otimes 0.05)$. Melan-A was expressed in 10 patients and the median survival rate was 29.0 month, the difference was not statistically significant $(P=0.728 \otimes 0.05)$. Vimentin was expressed in 7 patients and the median survival rate was 31.0 months, the difference was statistically significant $(p=0.022 \varangle 0.05)$.Figure9,10,11.

\subsection{Multivariate analysis of prognosis}

Put the variable quantity that was less than 0.05 which included primary sites, lymph node metastasis at first visit and the expression of Vimentin into COX regression model. It shows that only the variable factor that lymph node metastasis at first time was statistically significant and belong to the independent prognostic factor(Pख0.05), but the primary sites and the expression of Vimentin were not statistically significant( $(\mathrm{\otimes 0.05)(Table} \mathrm{2).}$

\section{Discussion}


Malignant Melanoma is a high grade tumor which origin from melanocyte, head and neck region is the predilection site, about $20 \%-35 \%$ cases occurred in the head and neck region ${ }^{[5]}$. Malignant Melanoma can occur in the skin or mucosa of head and neck, and the mucosal type have higher grade malignancy and poorer prognosis, lymph node metastasis and distant metastasis are common in mucosal type ${ }^{[6]}$. Compared with Euro-American countries, China had lower incidence rate, but recent years the incidence rate of Malignant Melanoma is rising across the world include China ${ }^{[7]}$. About the epidemiological characteristics of Malignant Melanoma of head and neck, the research in our country is lack. Some research suggested that the incidence rate of Malignant Melanoma occur in the mucosa of head and neck are higher in Asian and Africa country compared with western countries ${ }^{[8]}$. Malignant Melanoma of head and neck mostly occur in old people and rarely affect people under 30 . This research respectively analyze the clinical records of 15 patients treated in Shengjing Hospital of China Medical University and study the relationship between the prognosis and related clinical factors of Malignant Melanoma in head and neck.

\subsection{Relationship between prognosis and gender}

In 15 cases there were 9 male patients and 6 female patients, the male to female ratio was 1.5:1, which according to the related domestic records ${ }^{[9]}$. But some studies suggested that this ratio was different in different race or countries ${ }^{[10]}$, for example, in Gavriel's study, there are more female patients than male patients, that may because of different races or social and environment factors in different countries. In this study, according to analyze the medical records of malignant melanoma of head and neck, the result shows that gender has no effect on the prognosis of Malignant Melanoma(Pख0.05)『but in the research of Davar $^{[12]}$ it suggested that the prognosis of female patients were better than male patients ${ }^{[12]}$. It also showed that the hormone level of female patients and the defective BRAF gene can affect the prognosis of Malignant Melanoma of head and neck ${ }^{[13]}$. The difference between different researches may because of the different research objects and need to be further research.

\subsection{The relationship between prognosis and age}

Malignant Melanoma of head and neck mostly occur in older patients, and the peak age of incidence are 55 to 60 years old ${ }^{[14]}$. In this study, the average age of the patients are 40 years old, the oldest one is 75 years old. The research of Patel showed that the average age of patients is the main factor that affect the prognosis. Patients aged more than 60 years old had poorer prognosis but Hosokawa's research has opposite result ${ }^{[16]}$, age was not the independent prognostic factor and the prognostic difference between different age patients was not statistically significant. In this study patients were divided to two groups, there were 10 patients aged less than 60 years old, the median survival time was 31.5 months, there were 5 patients aged more than 60 years old and the median survival time was 29.5 years old. The result suggest that effect of age on prognosis was not statistically significant(Pख0.05).

\subsection{The relationship between prognosis and primary site}


Malignant Melanoma of head and neck include cutaneous Malignant Melanoma and mucosal Malignant Melanoma, obvious research showed that mucosal Malignant Melanoma had higher malignancy and poorer prognosis, lymph node metastasis and distant metastasis are commonly seen ${ }^{[17]}$.in this cases the primary sites included tongue, gingiva, lip, parotid and submandibular area. There are 7 patients occurred in gingiva which has the most cases, this result suggested that gingiva is the predilection site of oral mucosal malignant melanoma. In survival analysis, the univariate analysis suggested that the primary sites can affected the prognosis of patients(P®0.05), but in multivariate analysis, primary sites was not an independent prognostic factor $(P \otimes 0.05) \otimes$ this result was opposite with the research of Gavriel[11]. It suggested that the result may different in different races or because of the small sample size.

\subsection{The relationship between prognosis and treatment method}

Treatment method of Malignant melanoma included(1)treatment of the primary site; (2) treatment of the local metastasis (3) lymph node dissection $\mathbb{4} 4$ \treatment of distant metastasis. Surgical treatment is the primary treatment method of Malignant melanoma[13]. The scope of the resection needed attention in the resection of the primary site, which included the selection of safety incisal margin and the depth of resection. In 15 cases of our study, all patients were performed surgery to remove the primary site, and lymph node dissection for those patients have known lymph node metastasis. For those patients which have high risk lymph node metastasis performed preventive neck dissection.

Chemotherapy mostly used in advanced stage patients after the operation, DITC was commonly seen in chemotherapy of Malignant Melanoma in our country ${ }^{[14]}$. Most researches showed that Malignant Melanoma has poor sensitivities to radiation, so radiotherapy was less used after the surgery ${ }^{[15]}$. Because melanocytes was sensitive to low temperature, so cryotherapy was commonly used in the treatment of Malignant Melanoma[16]. Especially for the treatment of oral mucosal Malignant Melanoma, cryotherapy had obvious effect and can be used as the treatment of choice ${ }^{[5]}$. Along with the progress of technology, molecular therapy and immunotherapy gradually used in the treatment of Malignant Melanoma. Although in recent years immunotherapy and target therapy are continuous developing and significant effect, but in the medical treatment of Malignant Melanoma in our country, because of various reasons such as economic factors, traditional chemotherapy still has an irreplaceable status ${ }^{[17]}$. Based on whether to use chemotherapy, 15 patients has been divided to two groups, 6 patients were treated only by surgery, 9 patients treated by surgery combined with chemotherapy. The median survival time of chemotherapy group is 33.5 months, the median survival rate of non-chemotherapy group is 29.0 months, the difference between these two groups was not statistically significant $(P \otimes 0.05)$. This result was consistent with the research of Patrocco ${ }^{[18]}$, but opposite to the research of chapman ${ }^{[19]}$. It suggested that with or without chemotherapy was the independent prognostic factor that affect the prognosis of patients with Malignant Melanoma in head and neck.

\subsection{The relationship between prognosis and lymph node metastasis}


Malignant Melanoma is easy to have lymph node metastasis, especially for mucosal Malignant Melanoma in the head and neck ${ }^{[20]}$. In those patients, local lymph node metastasis were mostly seen at first visit, when there was definite lymph node metastasis, the regional lymph node dissection will be

performed. For Malignant Melanoma in head and neck, radical neck dissection should be performed ${ }^{[21]}$. Previous studies showed that lymph node metastasis were significant related with prognosis ${ }^{[22]}$. In this study, divided 15 patients to two groups, 8 patients were found lymph node metastasis at first visit, the median survival time was 28.9 months, 7 patients had no lymph node metastasis and the median survival time was 30.8 months, the difference was not statistically significant(Pख0.05). The diagnosis of lymph node metastasis should been based on clinical, radiological and histopathological examination. Early treatment should be performed for those have diagnosed lymph node metastasis. It suggested that lymph node metastasis as an independent prognostic factor, those patients which had lymph node metastasis at first visit had poorer prognosis and this result consist with the research of Griewank ${ }^{[23]}$.

\subsection{The relationship between prognosis with the expression of immune markers}

In recent years the expression of immune markers was considered related with the prognosis with Malignant Melanoma of head and neck ${ }^{[24]}$. Immunohistochemical examination was important in the

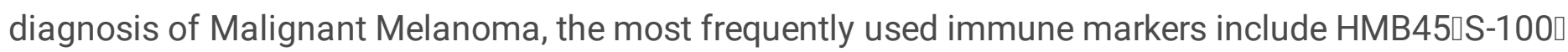
Vimentin and Melan- ${ }^{[25]}$. S-100 protein was an specificity protein, it usually exist in the cells of Malignant Melanoma, is an soluble protein which can be used as an immune marker in the diagnosis of Malignant Melanoma. Melan-A protein is also an specific protein which exist in the cytoplasm. HMB-45 is a specific monomer of Malignant Melanoma can interact with the tumor cells and can specially recognize the active and the inactive Malignant Melanoma cells. So HMB-45 is a immune marker which had lower sensitivity and higher specificity ${ }^{[28]}$. In this study, HMB-45 expressed in 12 patients and the median survival time was 31.0 months, Melan-A expressed in 10 patients and the median survival time was 29.0 months, Vimentin expressed in 7 patients and the median survival time was 31.0 months. Of all patients Vimentin was statistically significant in univariate prognostic analysis(Pख0.05), but in multivariate analysis, Vimentin had no effect on prognosis of patients and was not an independent prognostic factor. In study of Thompson ${ }^{[29]}$, HMB45 expressed patients had poorer prognosis than patients that HMB4 non-expressed, it suggested that HMB45 maybe the related prognostic factor of Malignant Melanoma. In study of Bottomley, it shows that Melan-A was the independent prognostic factor ${ }^{[30]}$. It suggested that in different groups, different immune markers had different effects on Malignant Melanoma of head and neck.

\subsection{Summary and prospect}

Malignant Melanoma was a high grade malignant tumor which has stronger invasion and poor prognosis. Malignant melanoma of head and neck often metastasis at early stage, especially those occur in oral mucosa. In our country malignant melanoma of head and neck had fewer cases and there is less studies about it. This study analyze the clinical features and prognostic factors of Malignant Melanoma of head and neck treated in our hospital but this study sample size was small and some medical records were not good enough. As the developing of biology technology, the treatment of Malignant Melanoma 
has made great progress but the prognosis was still poor, early diagnosis and early treatment still have important meaning. Physicians should be awareness of this disease and promote the development of new technologies and individualized treatment.

\section{Conclusion}

In this study Malignant Melanoma usually occurred in patients aged from 50 to 60 years old, the number of male patients were more than female.

In this study gingiva was the predilection site of Malignant Melanoma of head and neck.

In this study surgical treatment was the main method for the treatment of Malignant Melanoma, mostly combined with chemotherapy after the operation. Pathological examination and immunohistochemical examination were the main methods for diagnosis.

The prognosis of Malignant Melanoma was poor, univariate prognostic analysis suggested that primary sites, with or without lymph node metastasis at first visit and the expression of Vimentin were related with the prognosis $(P \otimes 0.05)$. The result suggested that with or without lymph node metastasis may be the independent prognostic factor of head and neck.

\section{Declarations}

\section{Data Availability Statement}

The authors confirm that the data supporting the findings of this study are available within the article and its supplementary materials.

\section{Conflict of Interest statement}

The authors confirm that there are no conflicts of interest.

\section{Author contribution statement}

XD Liu, WX Liu, QX wang contributed to the project design. XD Liu reviewed relevant literature, drafted the manuscript and conducted all statistical analyses. All authors read and approved the final manuscript.

\section{Funding statement}

This research received no specific grant from any funding agency in the public, commercial, or not-forprofit sectors. 


\section{Consent statement}

Informed consent was obtained from all subjects. Informed consent have been obtained from a parent and/or legal guardian for participants which are not available during follow up period.

\section{References}

1. Morton S K, Morton A P. Melanoma and pregnancy[J]. Australas J Dermatol,2017,58(4):259-267.

2. Lourenco SV, A MS, Sotto MN, et al. Primary oral mucosal melanoma: a series of 35 new cases from South America[J]. Am J Dermatopathol, 2009, 31(4):323-330.

3. Nathanson S D, Shah R, Rosso K. Sentinel lymph node metastases in cancer: Causes, detection and their role in disease progression[J]. Seminars in Cell \& Developmental Biology, 2015, 38:106-116.

4. Reed CM, Cresce ND, Mauldin IS, et al. Vaccination with Melanoma Helper Peptides Induces Antibody Responses Associated with Improved Overall Survival[J]. Clin Cancer Res,2015,21(17):3879-3887.

5. Larson DL, Larson JD. Head and neck melanoma[J]. Clin PlastSurg, 2010, 37(1):73-77.

6. Gavriel H, McArthur G, Sizeland A, et al. Review: mucosal melanoma of the head and neck[J]. Melanoma Res, 2011, 21(4):257-266.

7. Larson DL, Larson JD. Head and neck melanoma[J]. Clin PlastSurg, 2010, 37(1):73-77.

8. Prithviraj P, Anaka M, Mckeown S J, et al. Pregnancy associated plasma protein-A links pregnancy and melanoma progression by promoting cellular migration and invasion[J]. Oncotarget,2015,6(18):15953-15965.

9. Merkel E, Martini M, Amin S, et al. A comparative study of proliferative activity and tumor stage of pregnancy-associated melanoma (PAM) and non-PAM in gestational age women.[J].J Am AcadDermatol.2016,74(1): 88-93.

10. Tammaro A, Magri F, Moliterni E, et al. An uncommon localization of black heels in a free climbing instructor[J]. Int Wound J,2018,15(2):313-315.

11. Dragoslav Z, Jacob S, Besser M J. Immunotherapy for the management of advanced melanoma: the next steps.[J]. American Journal of Clinical Dermatology, 2013,14(4):261-272.

12. Davar D,Ding F,Saul M,et al. High-dose interleukin-2(HD IL-2)for advanced melanoma: A single center experience from the University of Pittsburgh Cancer Institute[J]. J Immunother Cancer,2017,5(1):74.

13. Weide B, Derhovanessian E, Pflugfelder A, et al. High response rate after intratumoral treatment with interleukin-2[J]. Cancer, 2010, 116(17):4139-4146.

14. Garcia M S, Ono Y, Martinez S R, et al. Complete regression of subcutaneous and cutaneous metastatic melanoma with high-dose intralesional interleukin 2 in combination with topical imiquimod and retinoid cream[J]. Melanoma Research, 2011, 21(1):65-65.

15. Patel F, Wilken R, Burrall B, et al. Detailed protocol for administration of intralesional IL-2 for the treatment of Stage IIIC and IV M1 a metastatic melanoma based on current NCCN guidelines[J]. Dermatology Online Journal, 2014, 20(11). 
16. Hosokawa S, Takahashi G, Okamura J, et al. Risk and prognostic factors for multiple primary carcinomas in patients with head and neck cancer.[J]. J Clin Oncol, 2018,.48(2): 124-129.

17. Mc Masters KM, Egger ME, Edwards MJ, et al. Final Results of the Sunbelt Melanoma Trial: A MultiInstitutional Prospective Randomized PhaseâđçStudy Evaluating the Role of Adjuvant High-Dose Interferon Alfa-2b and Completion Lymph Node Dissection for Patients Staged by Sentinel Lymph Node Biopsy[J].J Clin Oncol,2016,34(10):1079-1086.

18. Patrucco M S, Aramendi M V. Prognostic impact of second primary tumors in head and neck cancer[J]. Eur Arch Otorhinolaryngol,2016,273(7):1871-1877.

19. Yang AS, Chapman PB. The history and future of chemotherapy for melanoma.[J]. Hematol Oncol Clin North Am, 2009, 23(3):583-597

20. Moran B, Silva R, Perry AS, et al. Epigenetics of malignant melanoma[J]. Semin CancerBiol,2018,51(8):80-88.

21. Yang X, Ren GX, Zhang CP, et al. Neck dissection and post-operative chemotherapy with dimethyl triazeno imida-zole carboxamide and cisplatin protocol are useful for oral mucosal melanoma[J]. BMC Cancer, 2010, 10:623.

22. Rehan Akbani, Kadir C. Akdemir, B. Arman Aksoy, et al. Genomic Classification of Cutaneous Melanoma[J].Cell,2015,161(7):1681-1696.

23. Griewank KG, Scolyer RA, Thompson JF, et al. Genetical terations and personalized medicine in melanoma: progress and future prospects[J]. J Natl Cancer Inst, 2014,106(2):435.

24. Si L, Kong Y, Xu X, et al. Prevalence of BRAF V600Emutation in Chinese melanoma patients: large scale analy-sis of BRAF and NRAS mutations in a 432-case cohort[J].Eur J Cancer, 2012,48(1):94100.

25. Kroon H M, Coventry B J, Giles M H, et al. Australian Multicenter Study of Isolated Limb Infusion for Melanoma[J]. Annals of Surgical Oncology, 2015, 21:1-8.

26. E ggermont AM, Spatz A, Robert C. Cutaneous melanoma[J]. Lancet, 2014, 383(9919):816-827.

27. Nahar V K, Ford M A, Brodell R T, et al. Skin cancer prevention practices among malignant melanoma survivors: a systematic review[J]. Journal of Cancer Research\& Clinical Oncology, 2015:1-11.

28. Bartlett EK, Karakousis GC. Current staging and prognostic factors in melanoma [J].Surg Oncol Clin $N$ Am. 2015;24(2):215-27.

29. Coit DG, Thompson JA, Albertini MR, et al. Cutaneous Melanoma, Version 2. 2019, NCCN Clinical Practice Guidelines in Oncology[J].J Natl Compr Canc Netw,2019,17(4):367-402.

30. Bottomley A,Coens C,Suciu S,et al.Adjuvant therapy with pegylated interferon alfa- 2 bversus observation in resected stage III melanoma: a phase III randomized controlled trial of health-related quality of life and symptoms by the European Organization for Research and Treatment of Cancer Melanoma Group[J].J Clin Oncol,2009,27(18): 2916-2923.

\section{Tables}


Table 1. Basic situation of the research objects

\begin{tabular}{|c|c|c|c|}
\hline & Clinical parameters & $\begin{array}{l}\text { Number of } \\
\text { cases }\end{array}$ & $\begin{array}{l}\text { Constituent } \\
\text { ratio }\end{array}$ \\
\hline \multirow[t]{2}{*}{ age } & $\leq 60$ years old & 10 & $66.66 \%$ \\
\hline & $\$ 60$ years old & 5 & $33.33 \%$ \\
\hline \multirow[t]{2}{*}{ gender } & male & 9 & $60.00 \%$ \\
\hline & female & 6 & $40.00 \%$ \\
\hline \multirow[t]{2}{*}{ primary site } & oral mucosa & 7 & $46.66 \%$ \\
\hline & non oral mucosa & 8 & $53.33 \%$ \\
\hline \multirow{2}{*}{$\begin{array}{l}\text { lymph node metastasis at first } \\
\text { visit }\end{array}$} & yes & 8 & $53.33 \%$ \\
\hline & no & 7 & $46.66 \%$ \\
\hline \multirow[t]{2}{*}{ Distant metastasis at first visit } & yes & 2 & $13.33 \%$ \\
\hline & no & 13 & $86.66 \%$ \\
\hline \multirow[t]{2}{*}{ Treatment method } & combined with chemotherapy & 8 & $53.33 \%$ \\
\hline & $\begin{array}{l}\text { Non combined with } \\
\text { chemotherapy }\end{array}$ & 7 & $46.66 \%$ \\
\hline \multirow{4}{*}{$\begin{array}{l}\text { Immunohistochemistry } \\
\text { examination }\end{array}$} & HMB45 & 12 & $80.00 \%$ \\
\hline & Melan-A & 10 & $66.66 \%$ \\
\hline & Vimentin & 7 & $46.66 \%$ \\
\hline & S-100 & 15 & $100 \%$ \\
\hline
\end{tabular}

\section{Table2 coX regression multivariate analysis}

\begin{tabular}{|ll|}
\hline Variable factor & P value \\
\hline Primary sites & \\
\hline Lymph node metastasis at first visit & 0.467 \\
\hline Expression of Vimentin & 0.981 \\
\hline
\end{tabular}


Figures
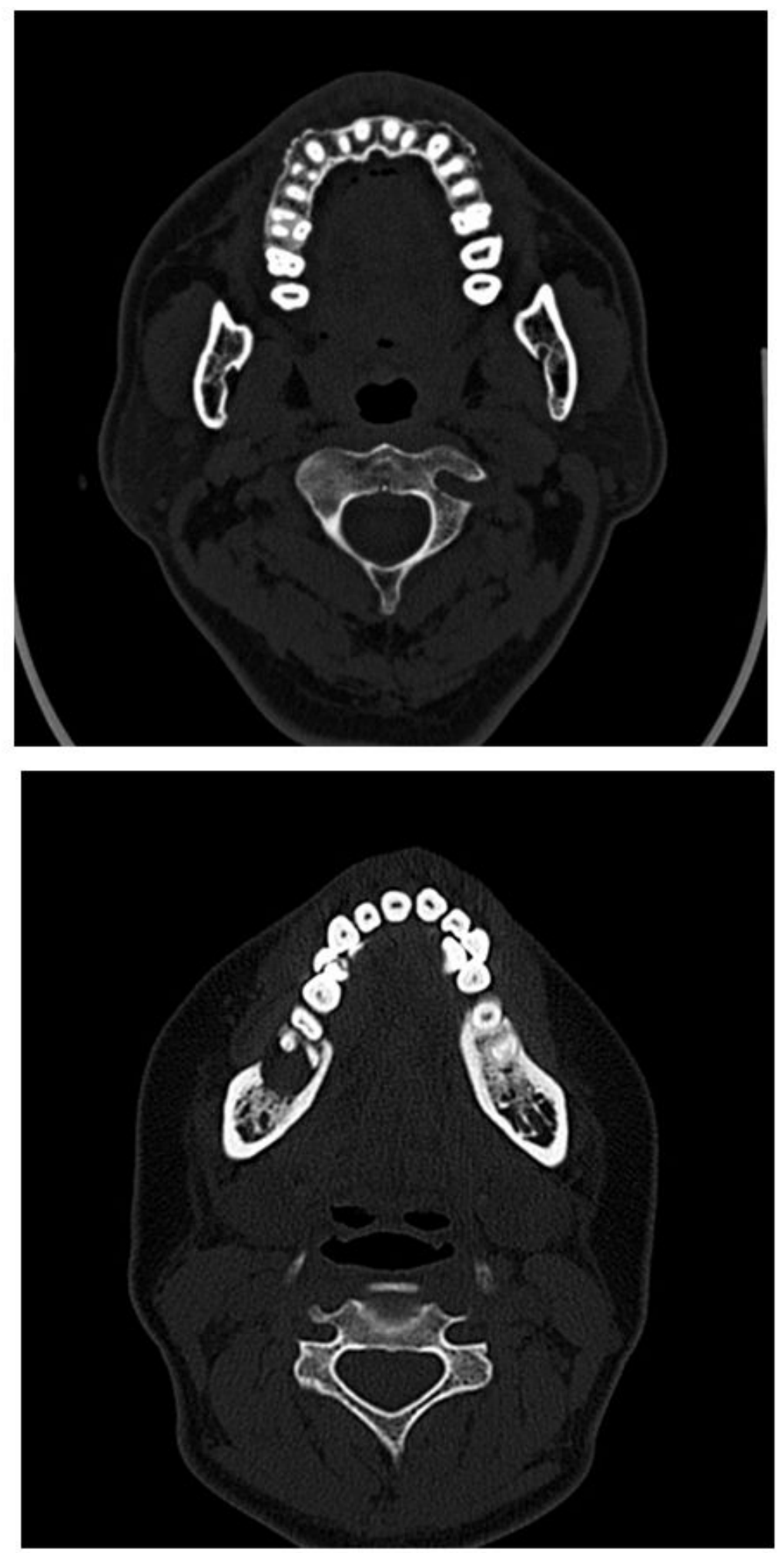

Figure 1

Imaging examination of Malignant Melanoma of gingiva(different cases) 

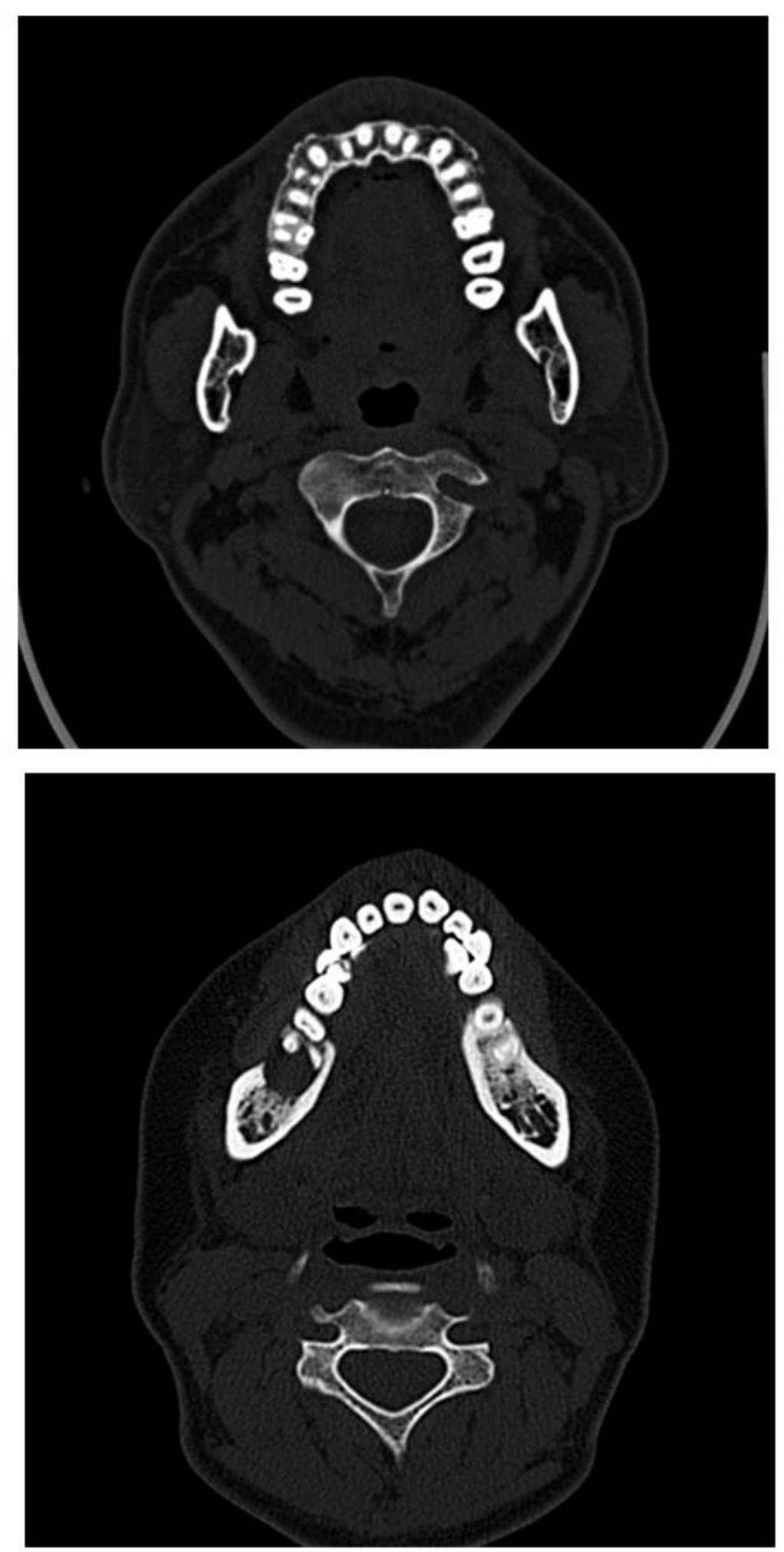

Figure 1

Imaging examination of Malignant Melanoma of gingiva(different cases) 


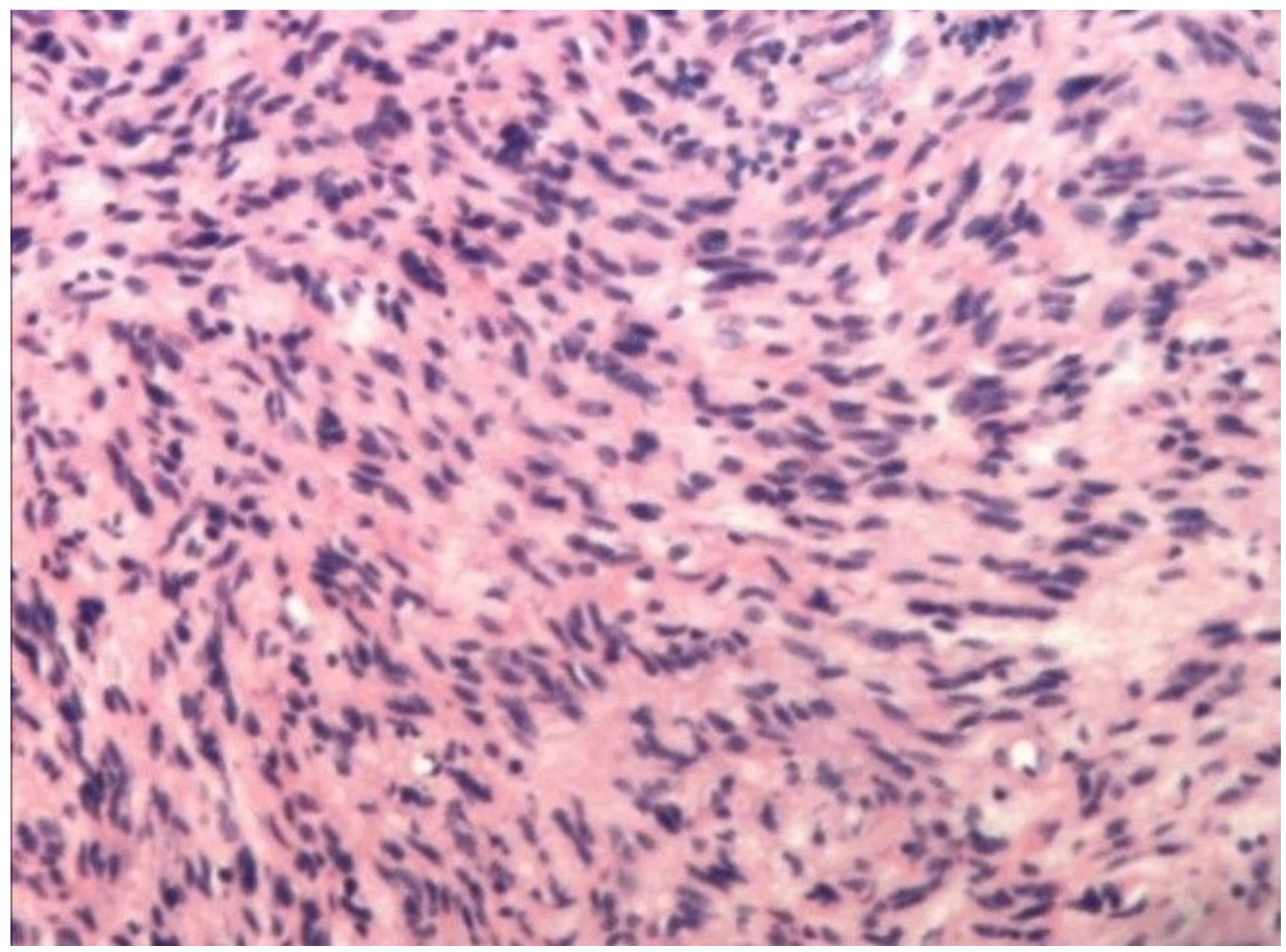

Figure 2

Spindle shaped tumor cells, obvious atypia, arranged in bundle 


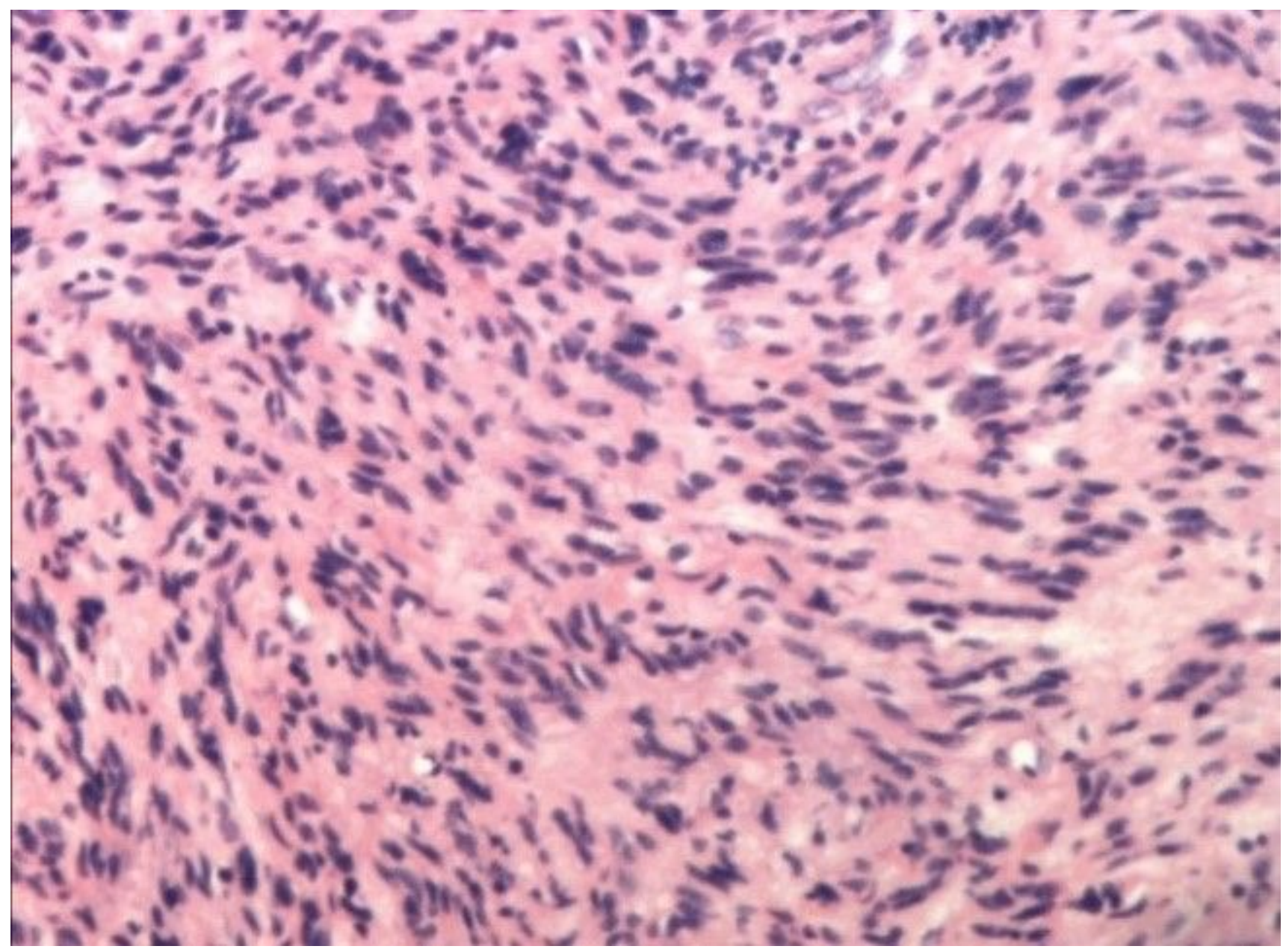

Figure 2

Spindle shaped tumor cells, obvious atypia, arranged in bundle 


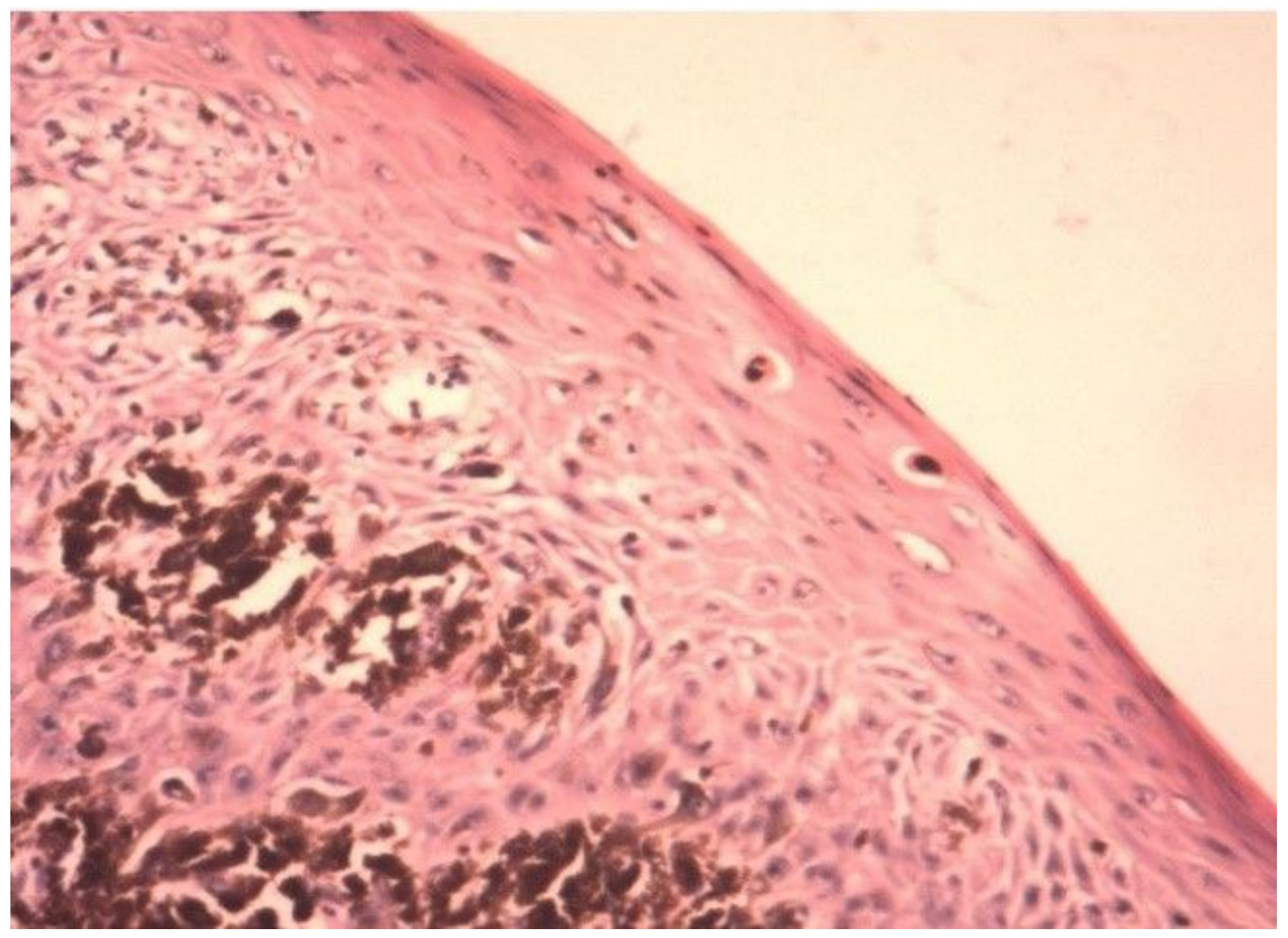

Figure 3

Tumor cells arranged diffusedly, lots of melanin can be seen 


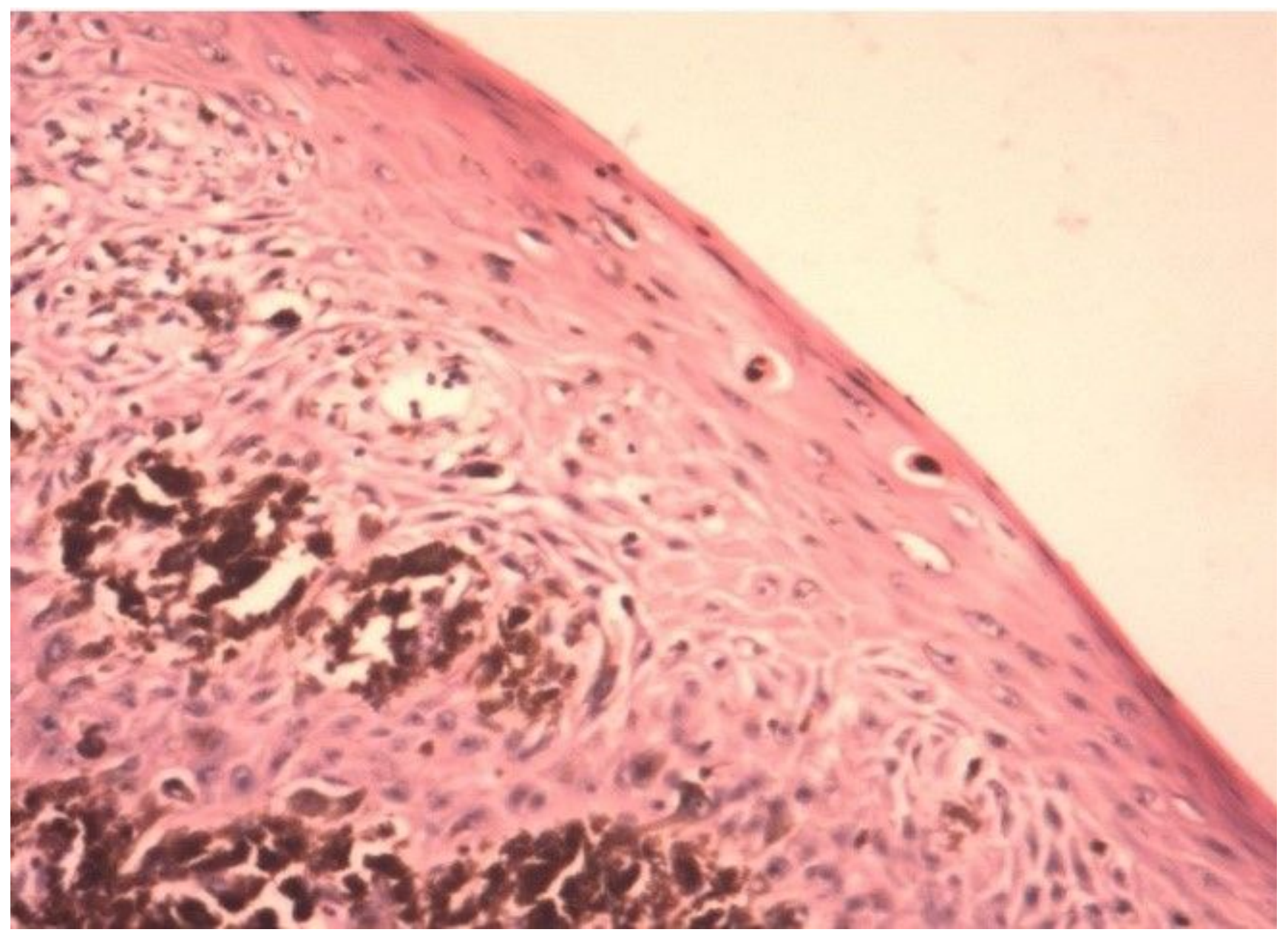

Figure 3

Tumor cells arranged diffusedly, lots of melanin can be seen 


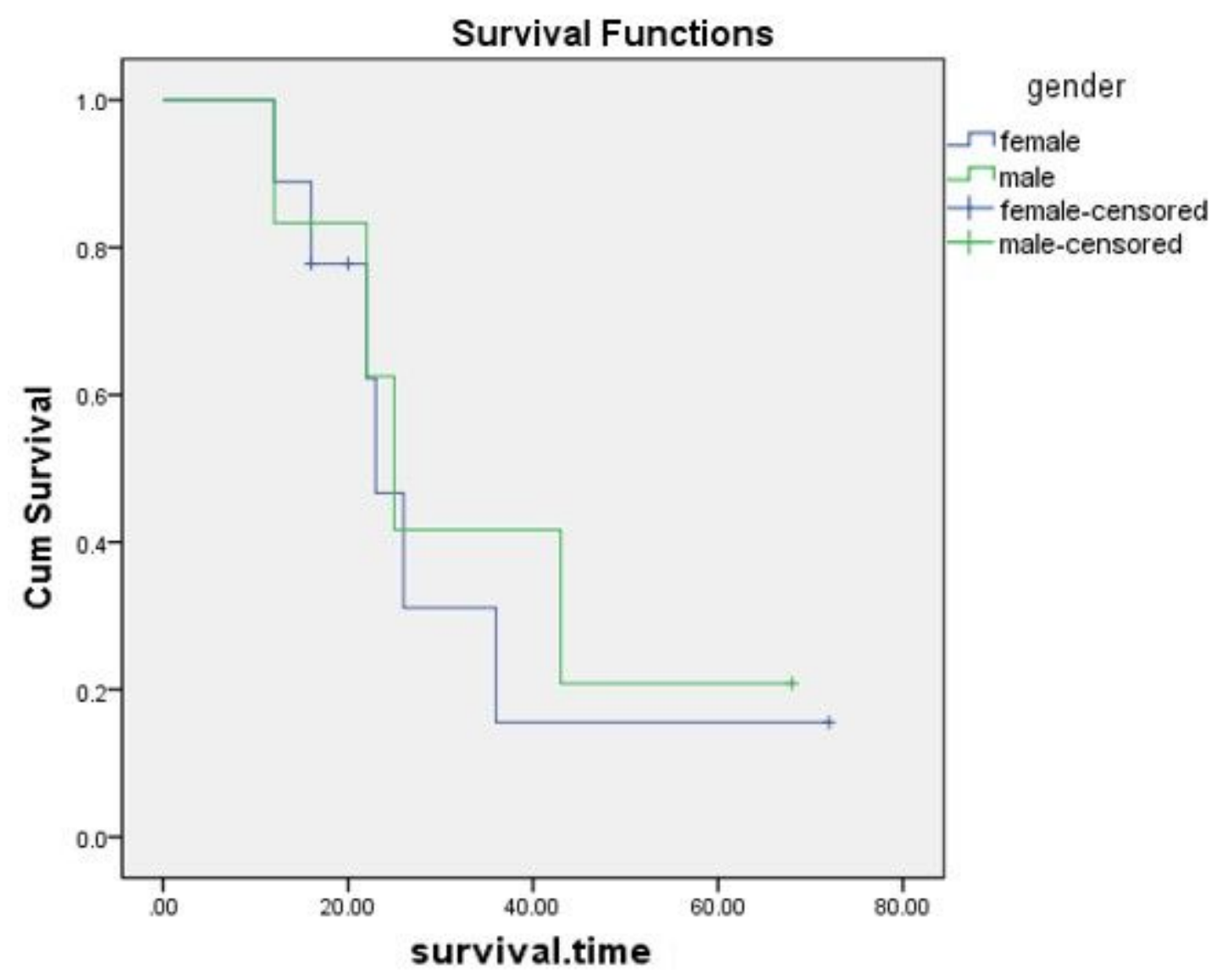

Figure 4

The relationship between prognosis and gender 


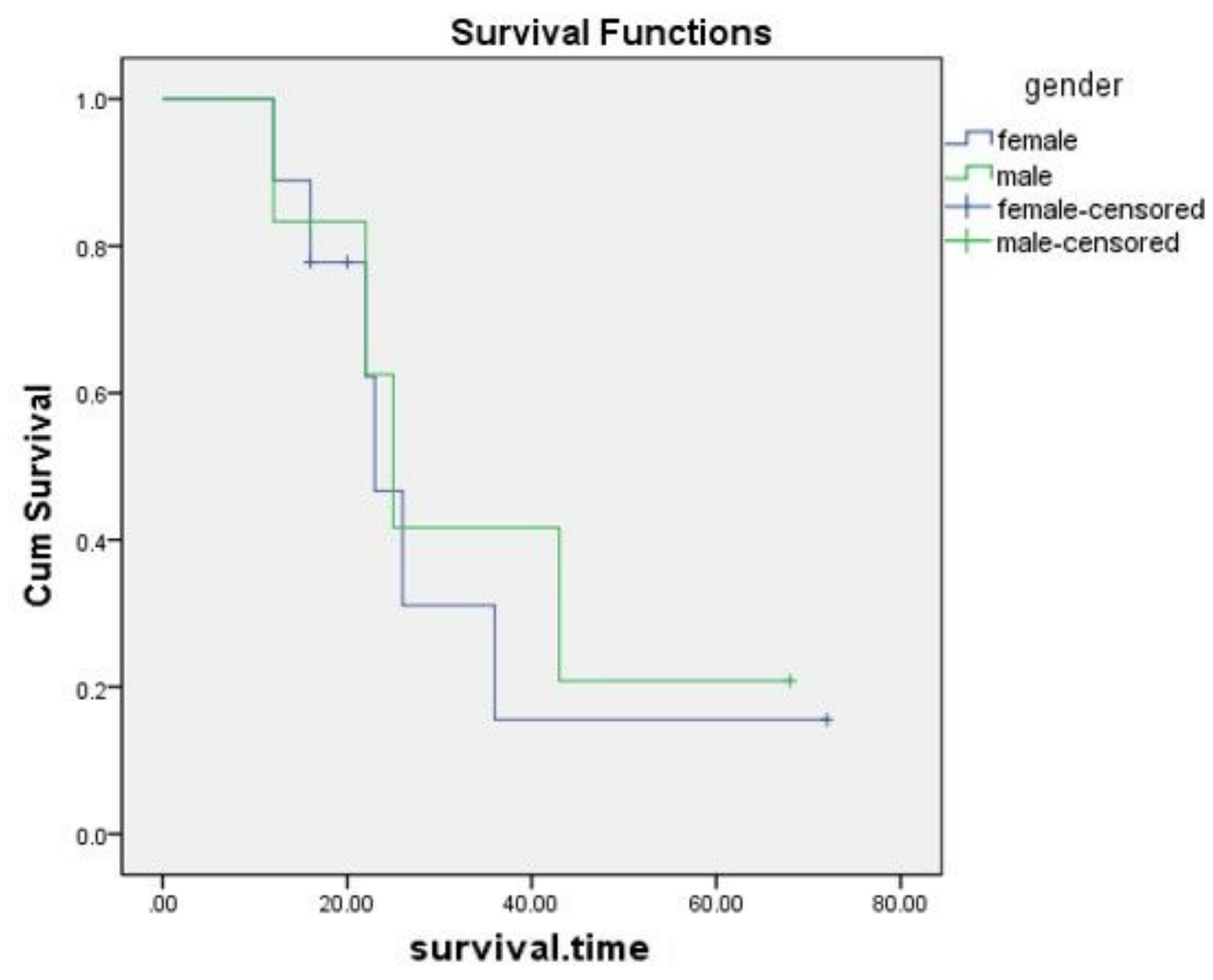

Figure 4

The relationship between prognosis and gender

\section{Survival Functions}

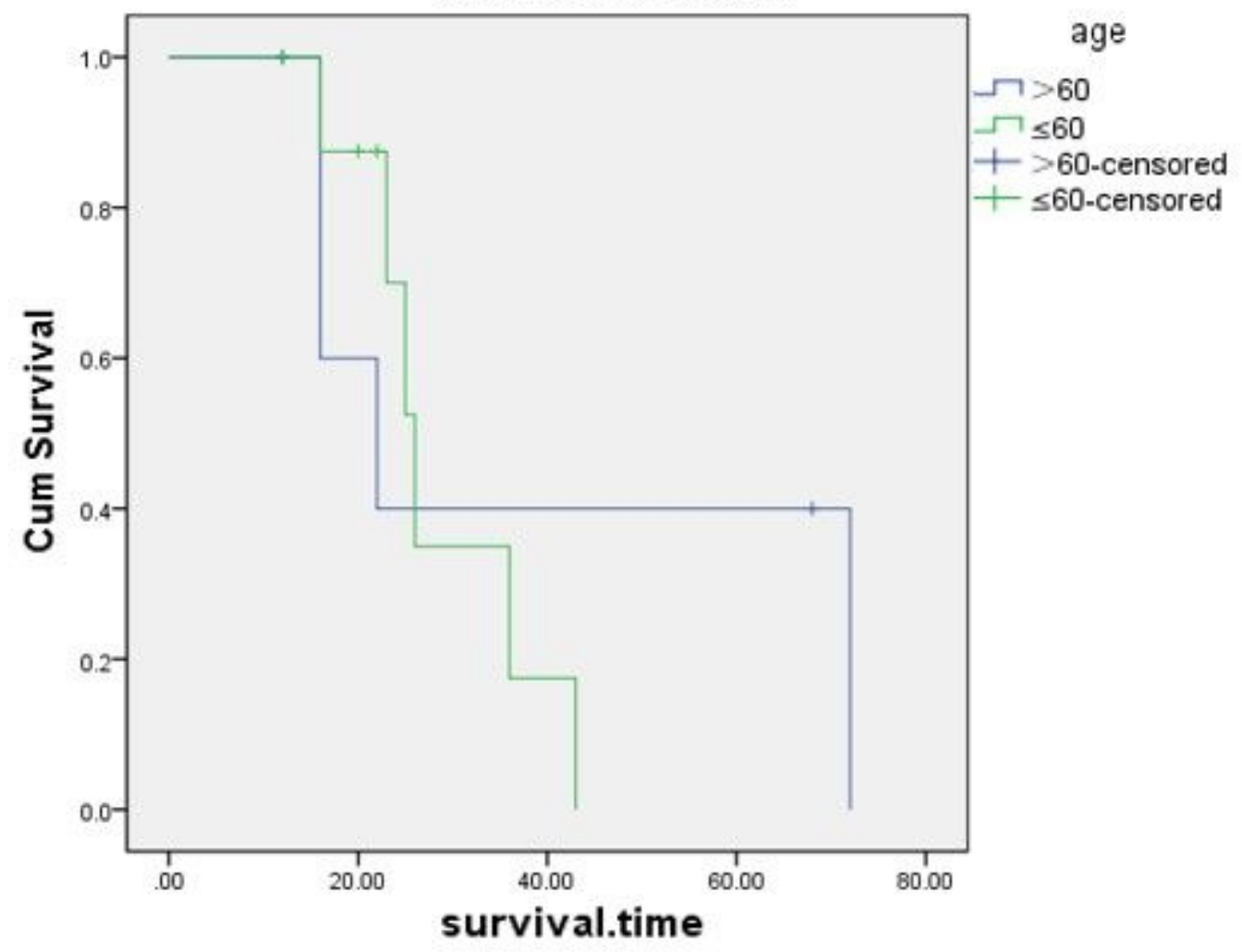


Figure 5

The relationship between prognosis and age

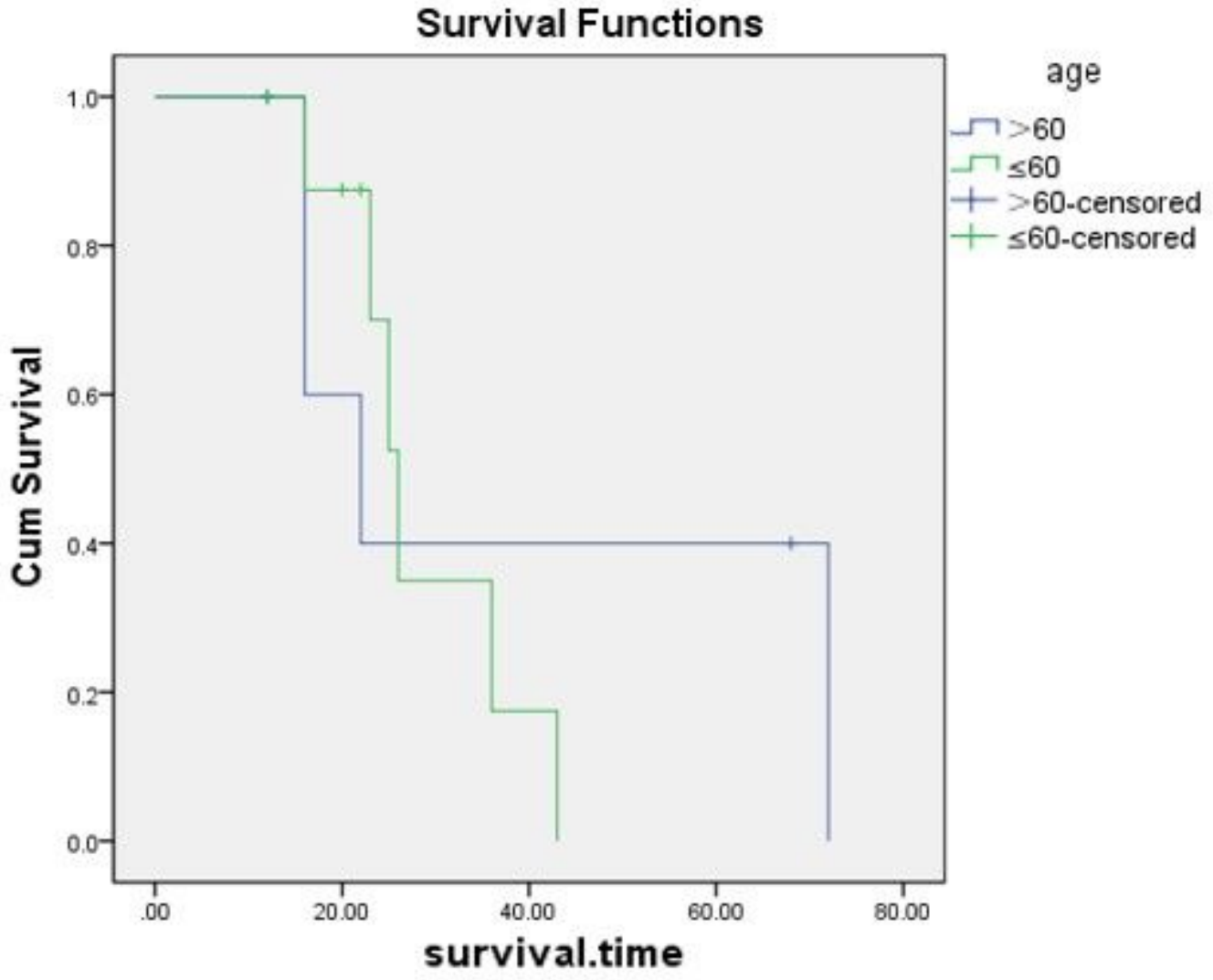

Figure 5

The relationship between prognosis and age 


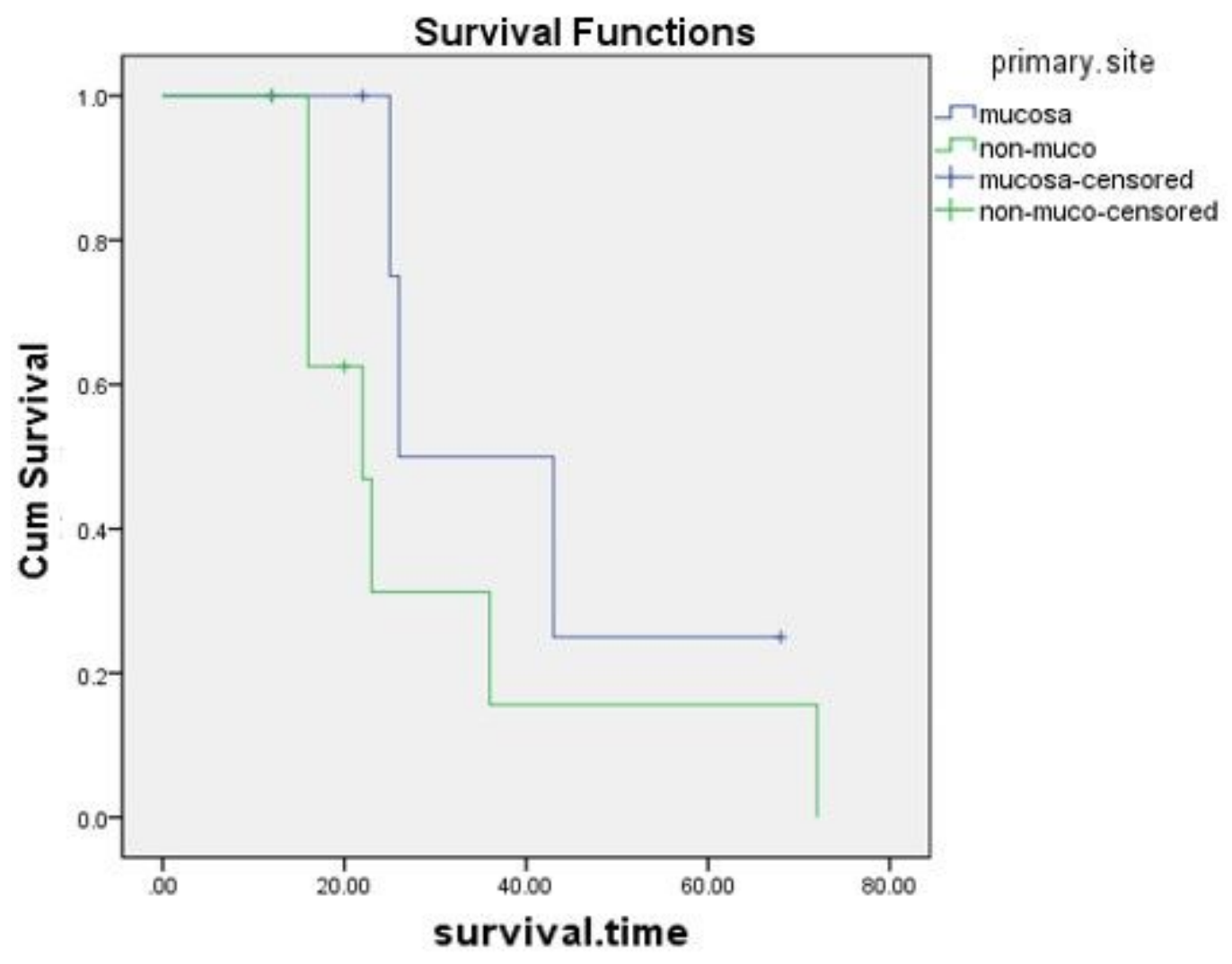

Figure 6

The relationship between prognosis and primary sites

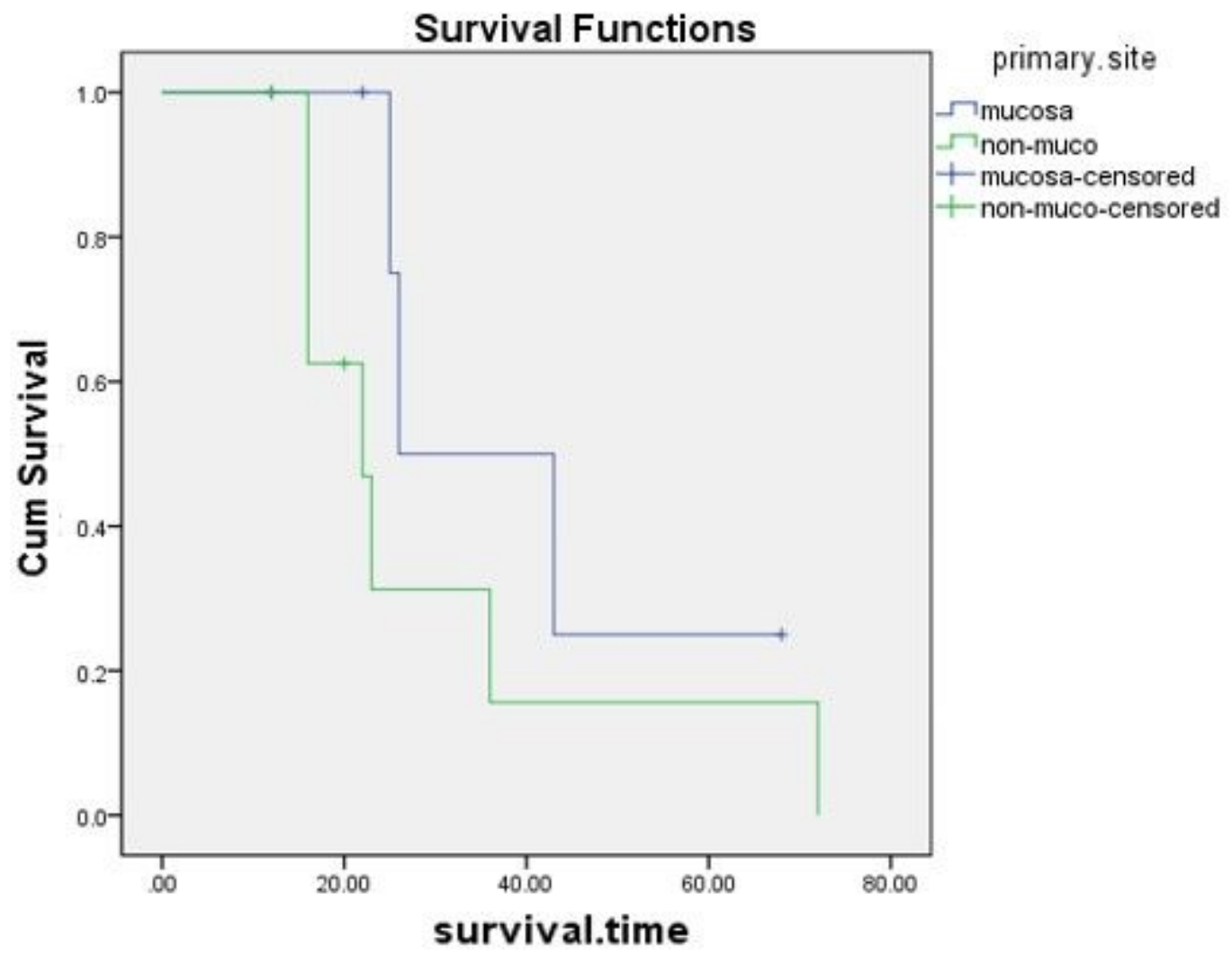

Figure 6 
The relationship between prognosis and primary sites

\section{Survival Functions}

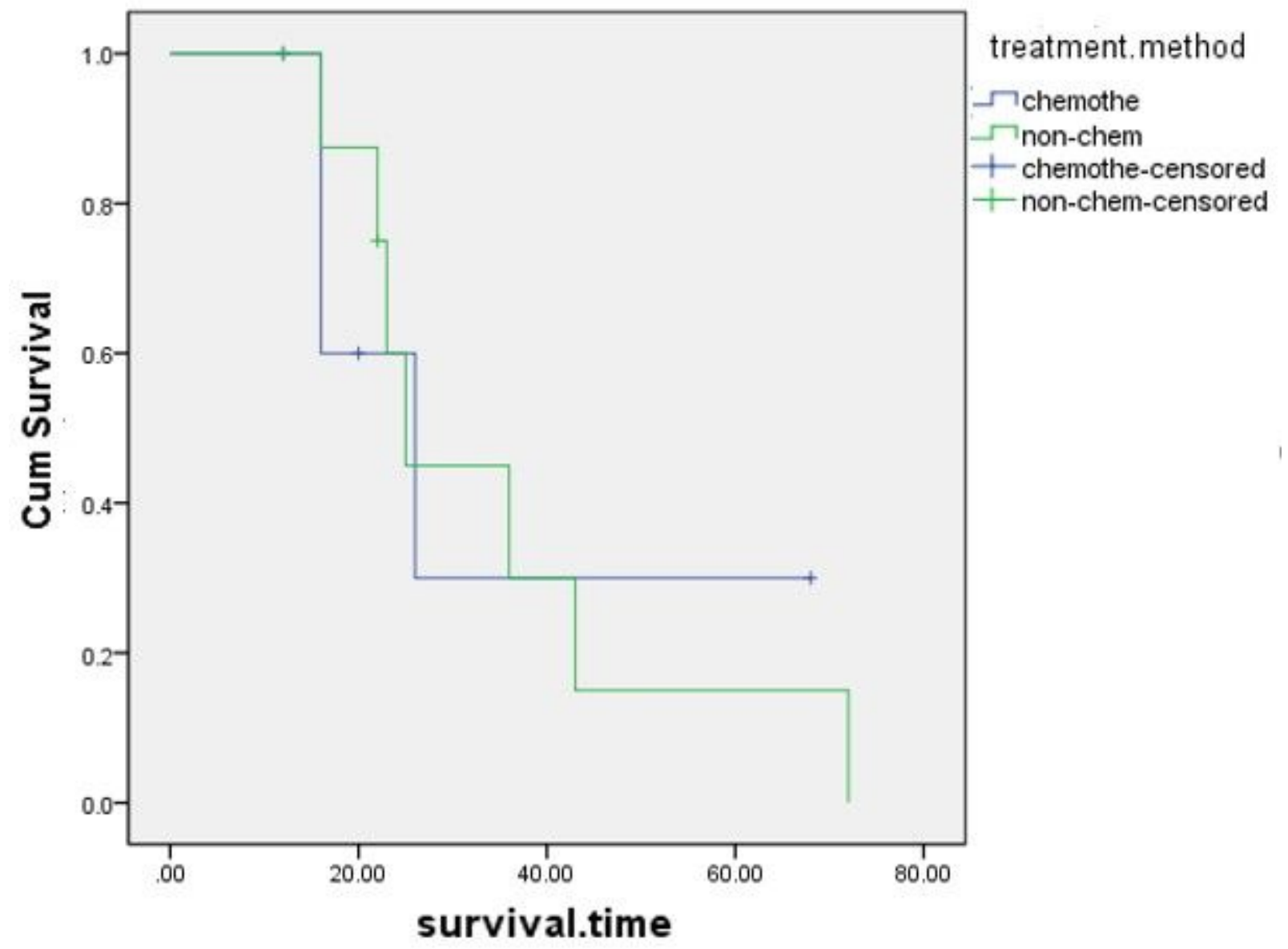

Figure 7

The relationship between prognosis and treatment method 


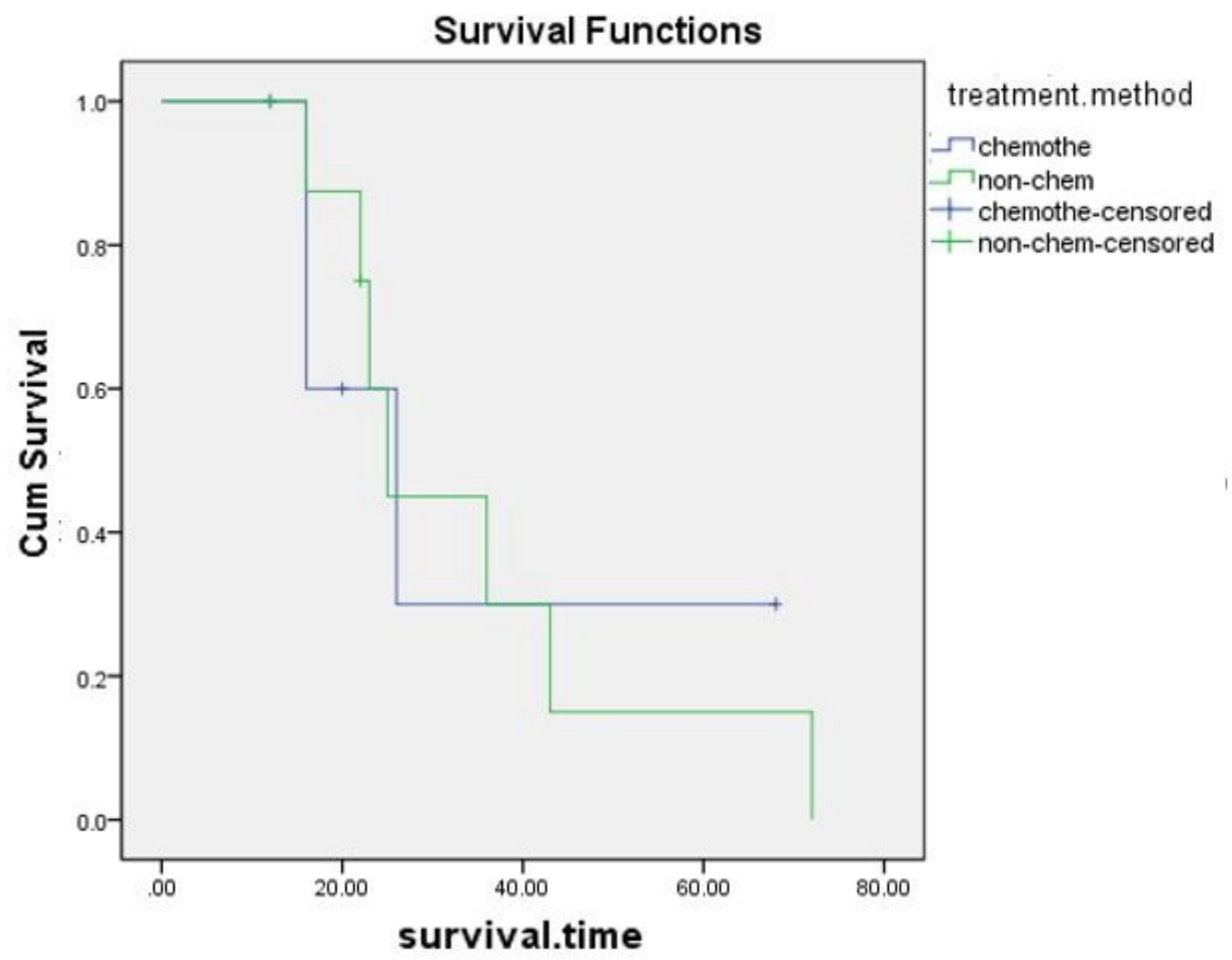

Figure 7

The relationship between prognosis and treatment method 


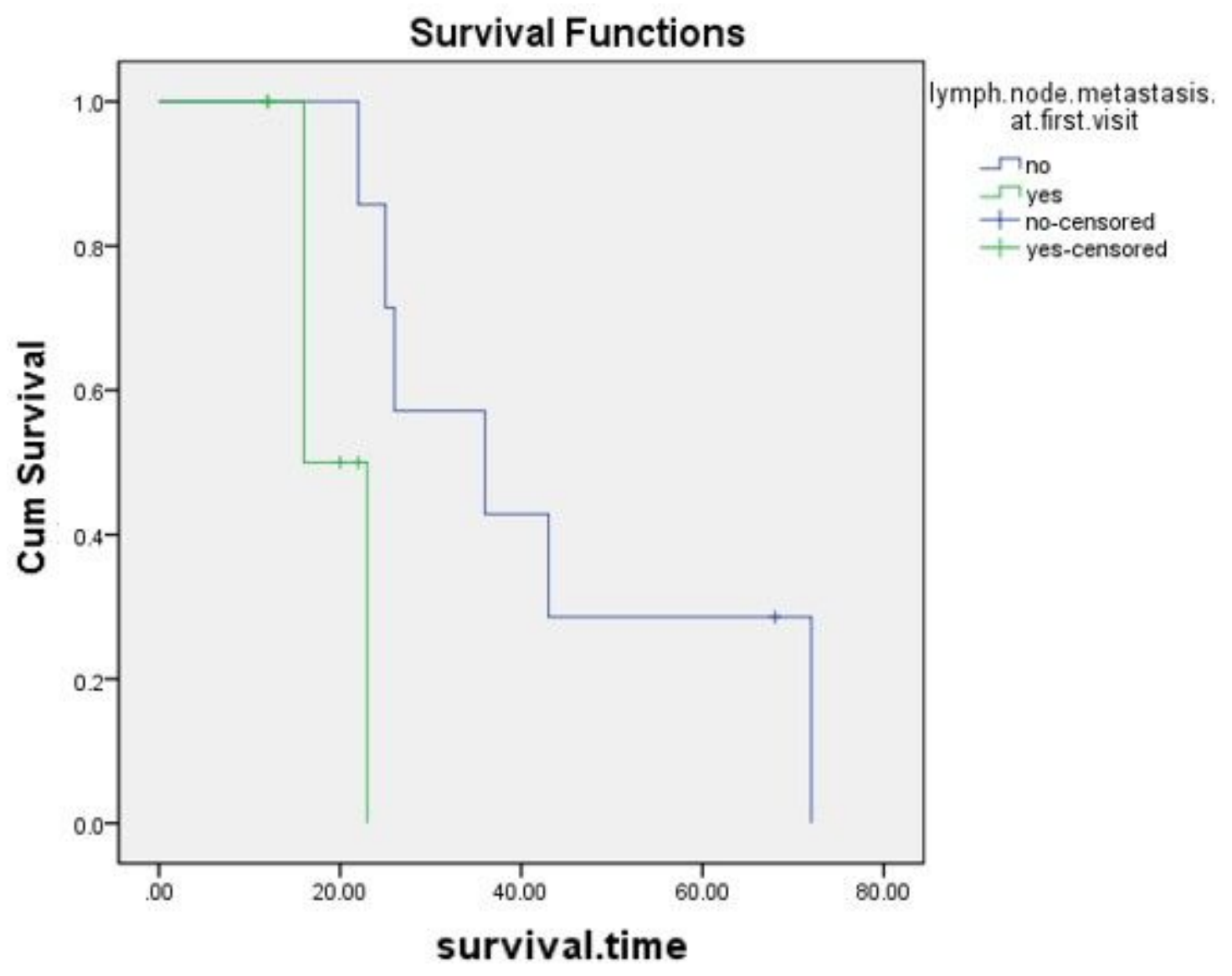

Figure 8

The relationship between prognosis and lymph node metastasis at first visit 


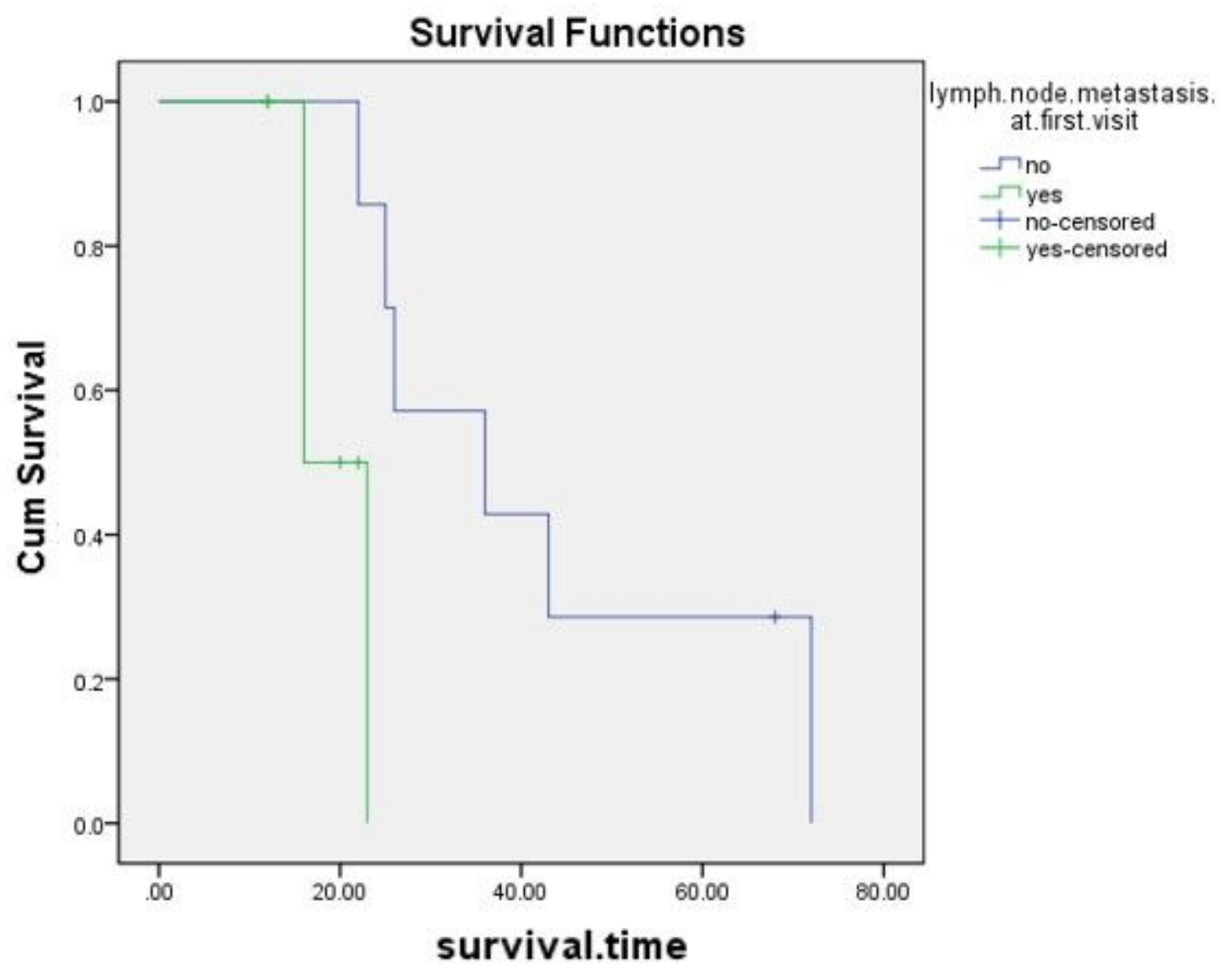

Figure 8

The relationship between prognosis and lymph node metastasis at first visit 


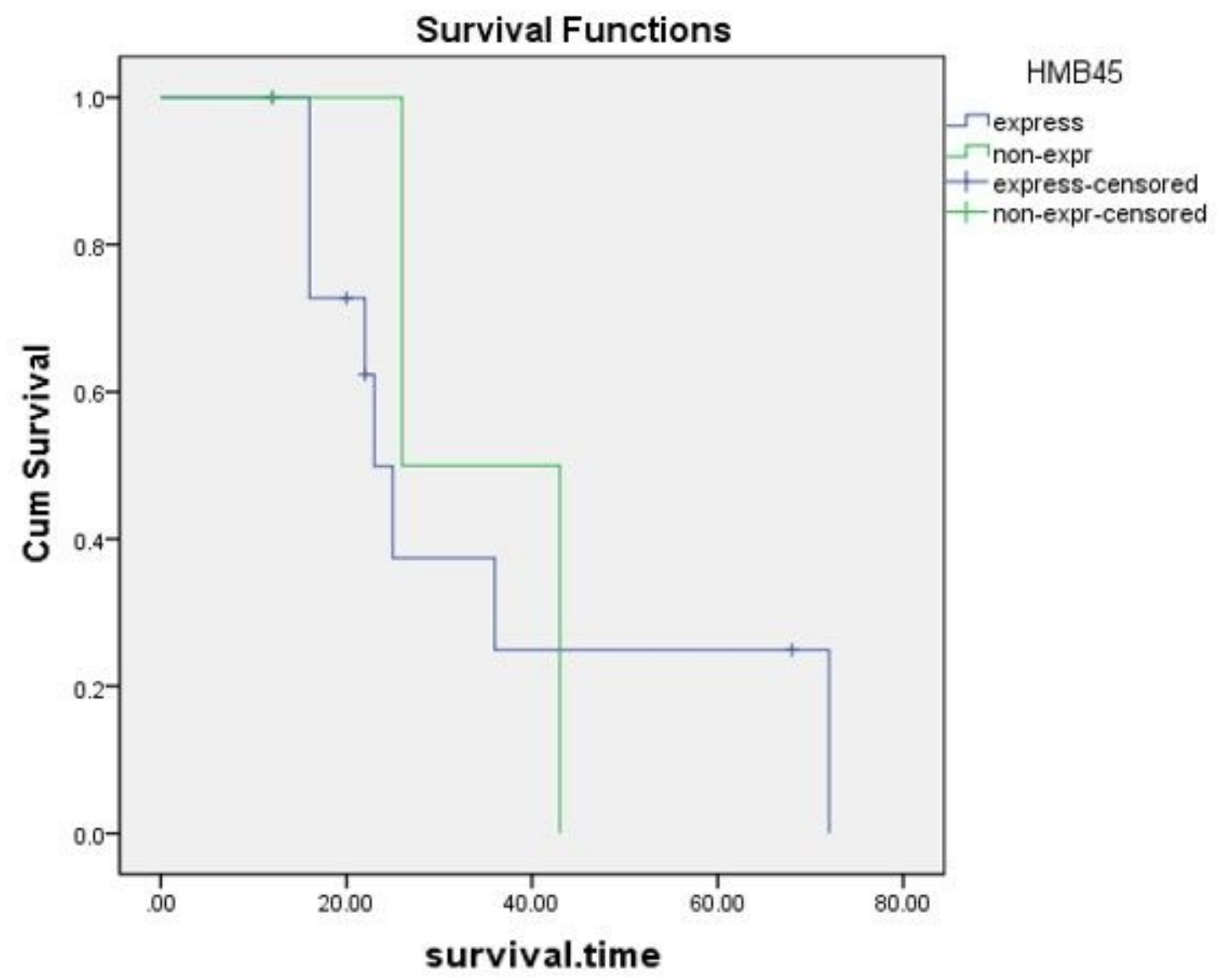

Figure 9

The relationship between prognosis and the expression of HMB45 


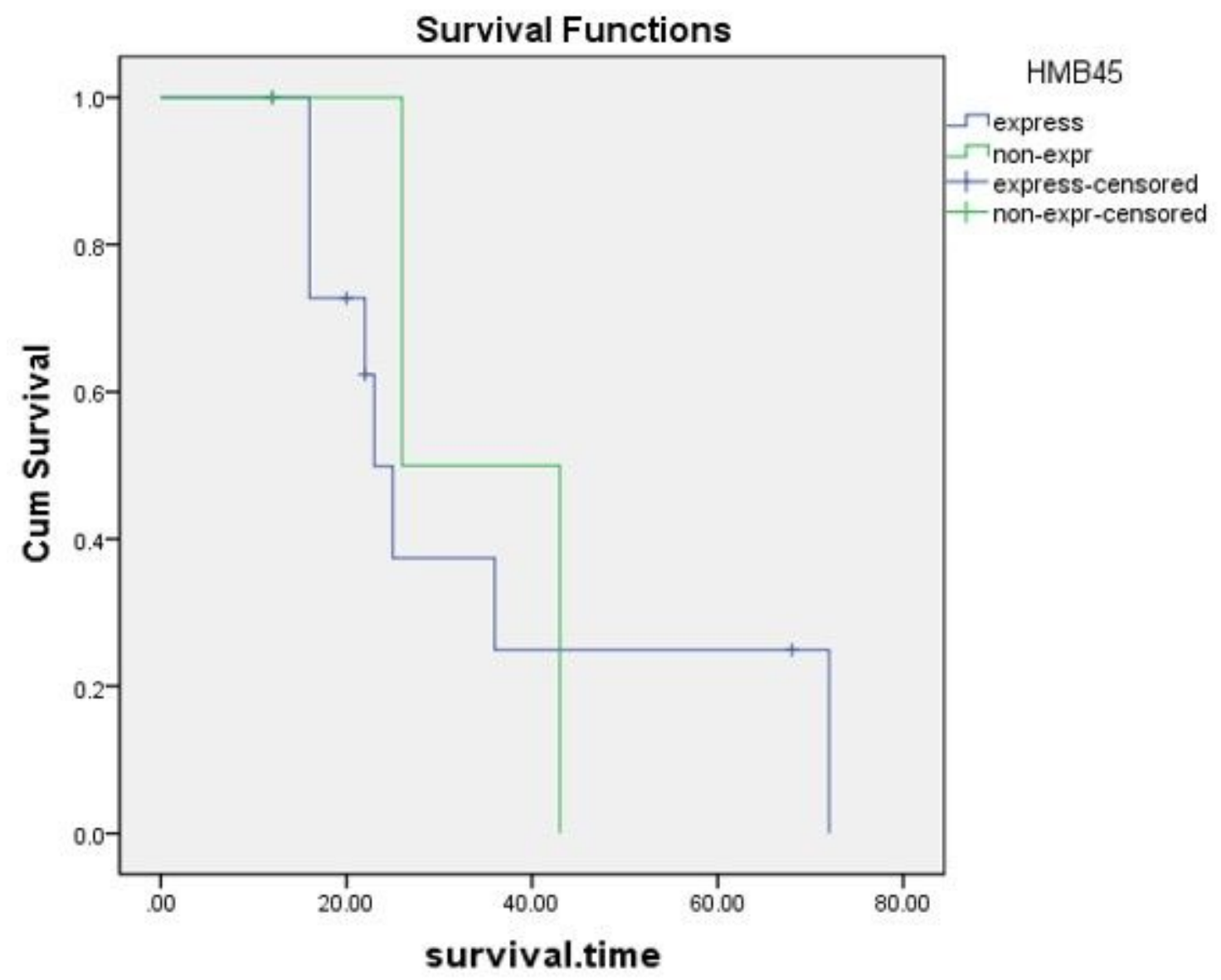

Figure 9

The relationship between prognosis and the expression of HMB45 


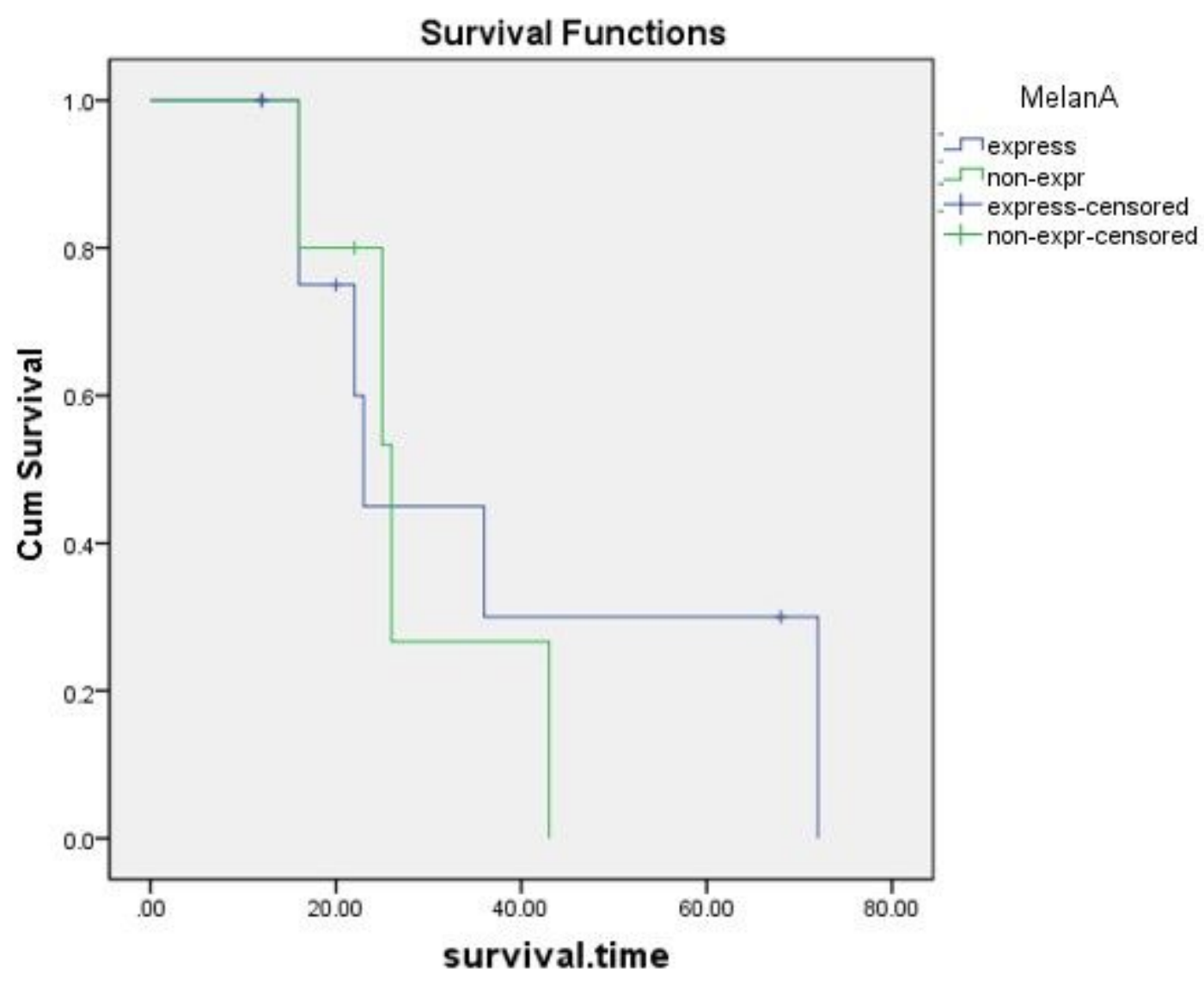

Figure 10

The relationship between prognosis and the expression of Melan-A 


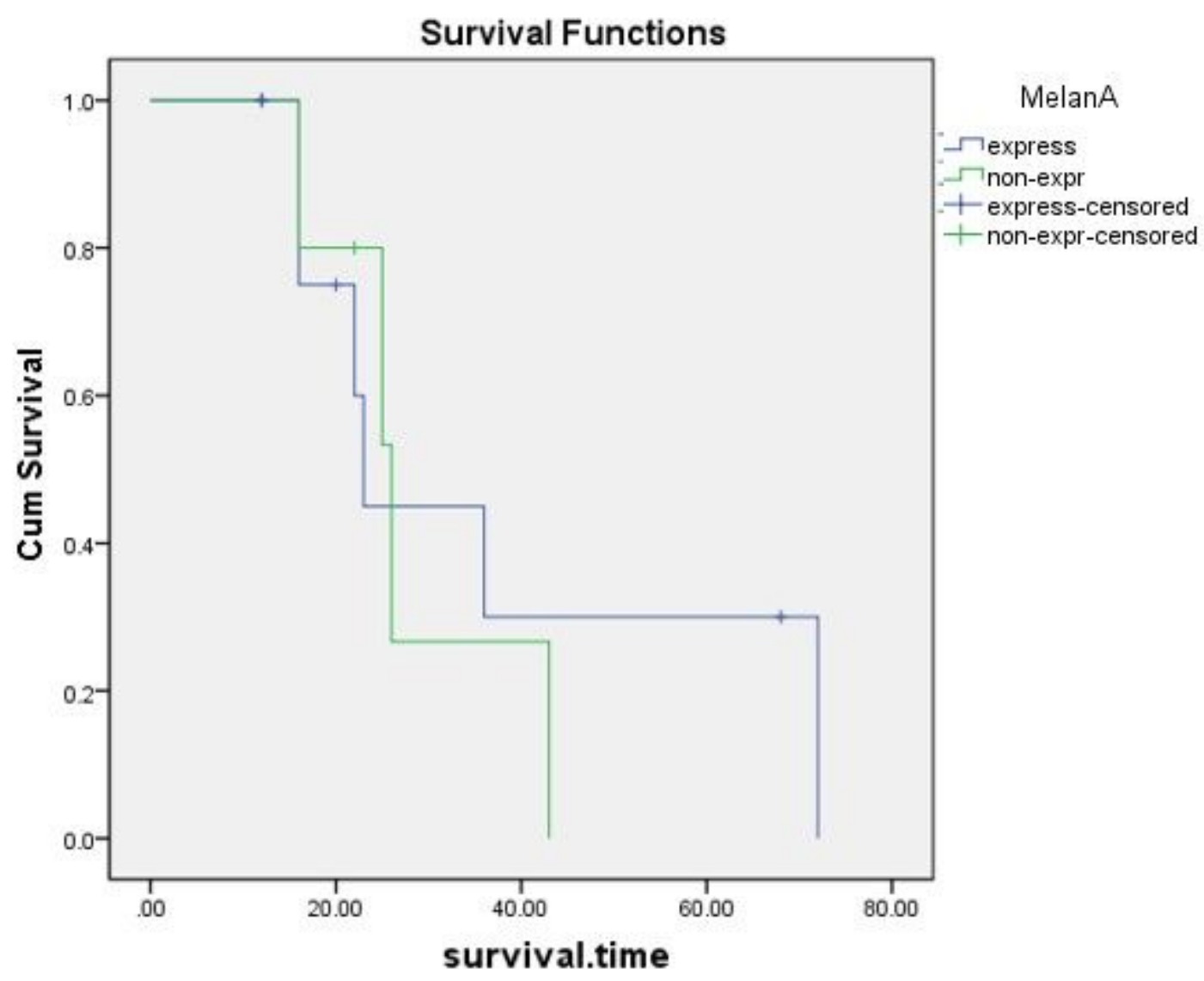

Figure 10

The relationship between prognosis and the expression of Melan-A 


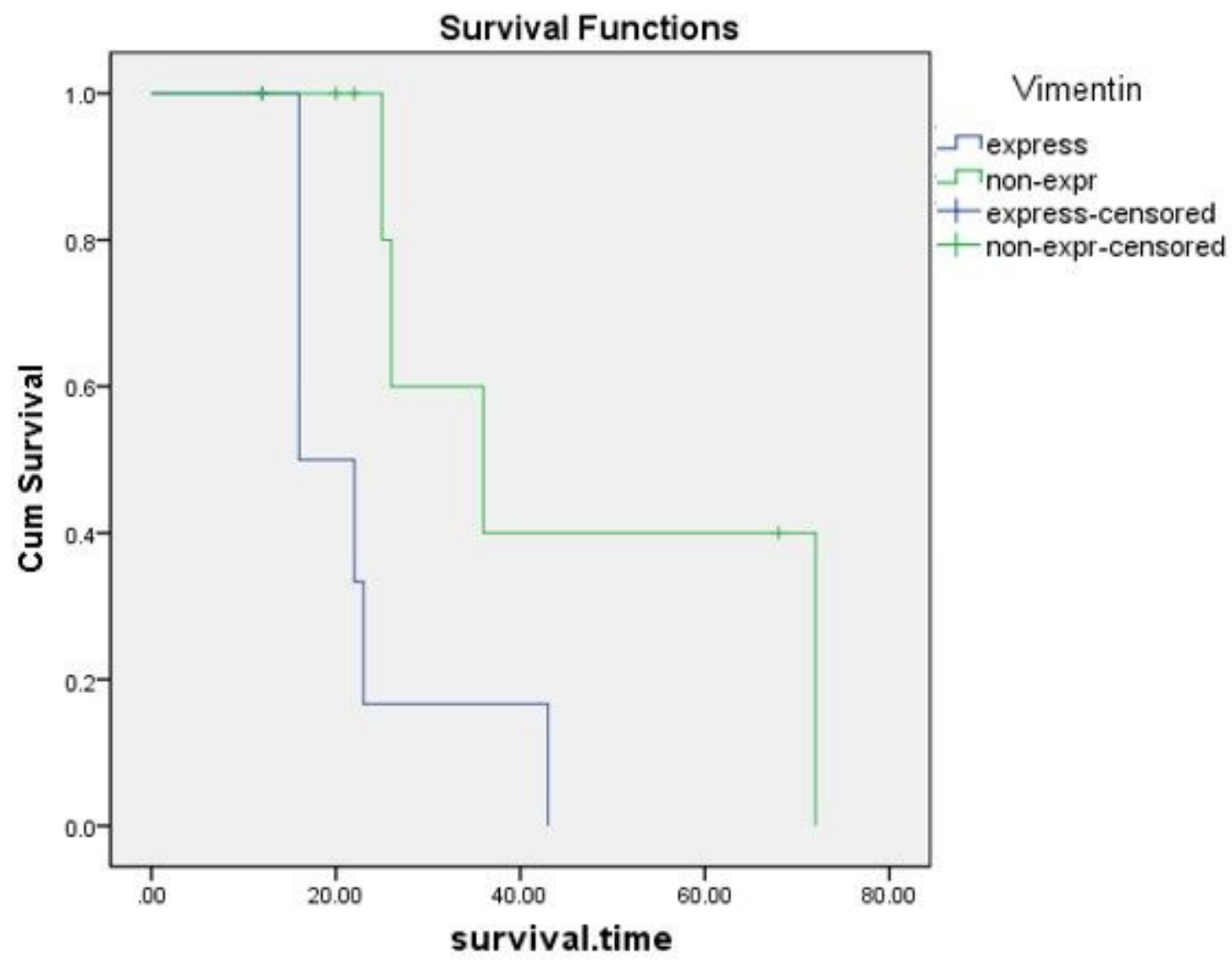

Figure 11

The relationship between prognosis and the expression of Vimentin 


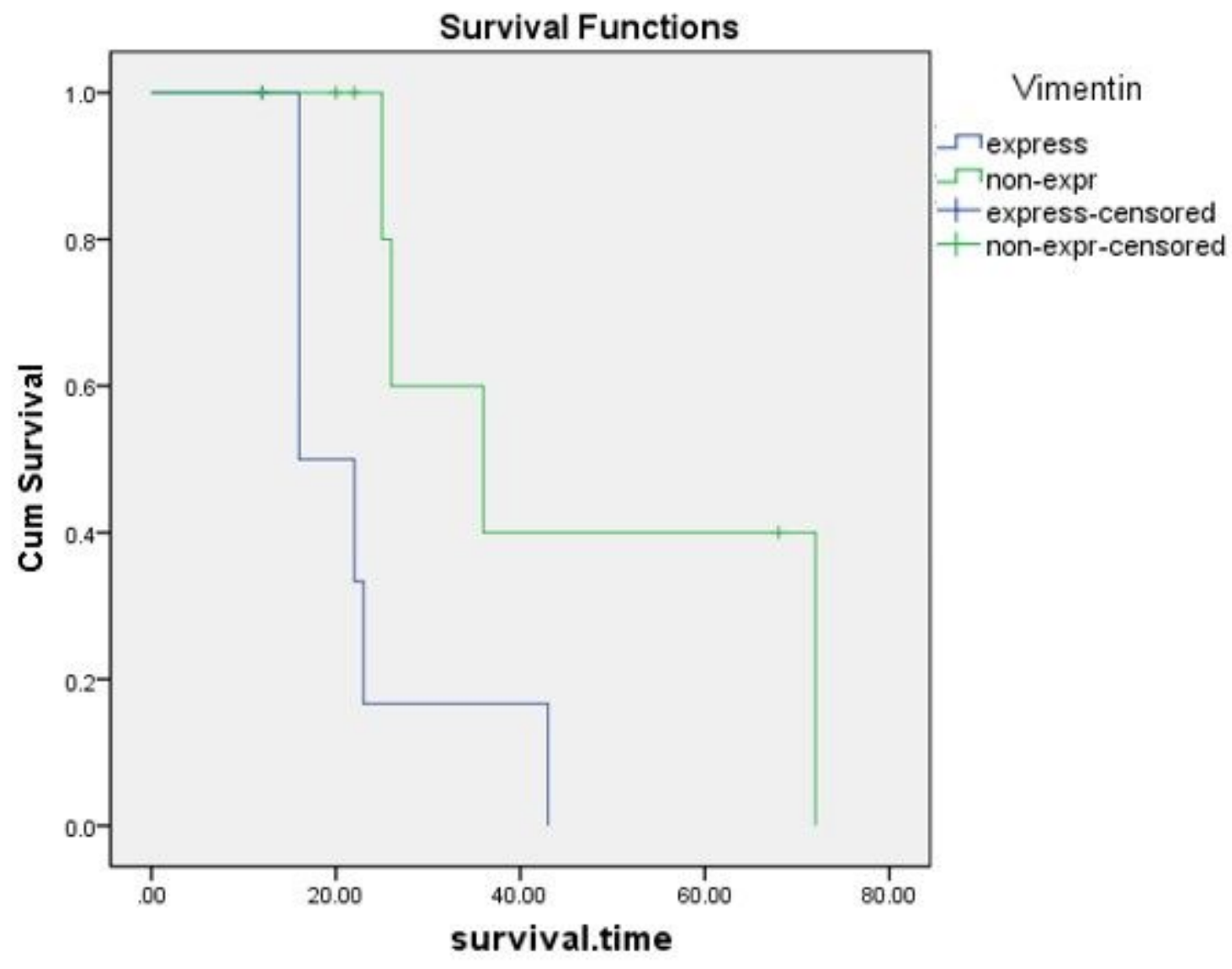

Figure 11

The relationship between prognosis and the expression of Vimentin 